\title{
Reexamining the Market for Judicial Clerks and Other Assortative Matching Markets
}

\author{
George L. Priest ${ }^{\dagger}$
}

For many decades, scholars have puzzled over why the market for judicial clerks has been characterized by increasingly early bidding, with interviews and offers extended at progressively early points in a student's law school career. An important article published recently by Avery, Jolls, Judge Posner, and Roth reported the results of a study the authors conducted of judges and clerks documenting the many ways in which the market operated inefficiently. In their view, the clerk market corresponds to other markets studied, chiefly by Roth, that show timing disturbances claimed to be market failures. The authors recommended adoption of a modified matching program, similar to the program that matches medical residents with hospitals.

This paper reanalyzes the clerkship market and the other markets studied by Professor Roth from the standpoint of the costs and benefits of information acquisition. It shows that, far from market failure, the use of time as a currency in the market represents the working out of market forces where other, more traditional terms of trade-in particular, price-are unavailable. This paper also shows that virtually all of the other markets studied by Roth that show timing peculiarities are characterized by restraints on the use of price to clear the market.

Introduction: The Nature of the Problem

I. The Current Understanding of Markets with Timing Problems 128

A. The History of Disorders in the Market for Federal Judicial

Clerks.

$\dagger$ John M. Olin Professor of Law and Economics, Yale Law School. I am grateful to Orley Ashenfelter and Edward J. Brunet for various discussions on topics related to this paper, to Christine Jolls and Richard A. Posner for comments and for their help in obtaining data from surveys of federal appellate judges and students that they and co-authors conducted in 2000, to Marilyn Drees for providing materials regarding recent efforts to control the process, to Anne Alstoth, Ian Ayres, Peter Carstensen, David Haddock, Alex Kozinski, Scott Masten, Fred McChesney, Claire Priest, Carol Rose, Peter Schuck, Alan Schwartz, Stephen F. Williams and participants at workshops at Chicago, Harvard, Michigan, Northwestern, Toronto, and Yale Law Schools, as well as the Meetings of the American Law and Economics Association for comments on earlier drafts, to James Hunter, Tibor Nagy, and Thomas J. Obhof for research assistance and to Nicholas K. Priest for help with the empirical work. The usual expectation of scholarly disinterest in the topic is impossible to satisfy here. I have been involved in the judicial clerk market as a reference for over 20 years and am personally acquainted with almost all of the distinguished judges whose work on this topic I address; many are friendssome, close friends. I have tried to remain as objective as possible throughout. 
B. The Harvard-Chicago Analysis of the Market ................................134

1. The Normative Framework ................................................... 134

2. Empirical Findings ............................................................135

3. The Harvard-Chicago Recommendations ................................139

C. The Broader Context of Market Unraveling .................................. 142

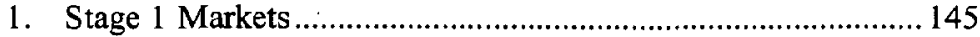

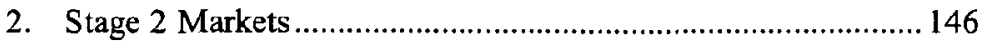

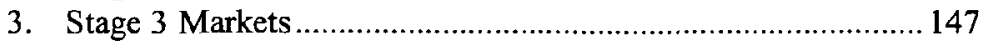

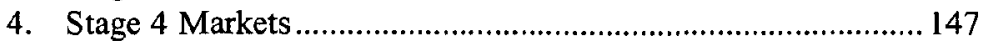

5. Other Markets with Unraveling ................................................. 148

II. A Different Approach Toward the Timing of Market Transactions......... 149

A. Markets with Timing Peculiarities from the Vantage of Market Search

B. The Harvard-Chicago Critique of the Market for Judicial

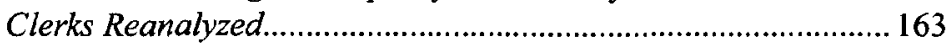

C. The Curious Case of Yale Law School ........................................... 177

D. A Reanalysis of Unraveling in the Other Markets Identified by Professor Roth

1. Time-of-Offer Currency Markets Reviewed................................ 187

2. Markets Where Timing Is a Means of Avoiding Regulation.... 195

3. Summary

III. Judicial Disrepute and the Ethics of Practices in the Market for

Clerks

IV. Conclusion

Introduction: The Nature of the Problem

The principal interest of academics in the market for judicial clerks has been in how to regulate it. Building on the concerns of some judges, the exclusive focus has been on how to control the problematic timing of the market transactions in which the judge selects the clerk. The perceived harm is that competition for clerks among judges-especially appellate judges-has begun earlier and earlier in students' law school careers, when there is limited evidence of the student's law school performance upon which to base the selection. Over the past decade, there have been various efforts to control the process by groups of law school deans-for example, by setting uniform application or faculty recommendation dates. ${ }^{1}$ And there have been attempts by the Judicial Conference and other assemblies of appellate judges to restrain the times at which judges begin the application and interview process.

1 As will be described, two recent deans of Yale Law School have been particularly active in pressing for reforms of this nature. 
Most recently, this past March 2002, an ad-hoc committee of federal appellate judges organized a referendum among their colleagues that endorsed a one-year moratorium on hiring clerks. ${ }^{2}$ By this means, judges complying with the moratorium deferred for a year consideration of candidates who, in the previously unregulated process, would be applying at the beginning of their second year of law school, to only accept applications a year later from candidates who will be beginning their third year. This hiring moratorium was not strictly binding on the appellate judiciary, ${ }^{3}$ though it has been equally endorsed by a large group of law school deans who have pledged to employ their influence on their faculties and students to abjure from earlier participation in the application process. ${ }^{4}$ The moratorium appears to have been generally successful, postponing the operation of the clerkship market-for the year 2003, at least—until the beginning of the applicants' third year of law school, though there are apparently some circuits and some individual judges who have complained about the compressed time frame for decision that results. Even more recently, in December 2003, the Ad Hoc Committee endorsed adoption of the plan again for the 2004 hiring year, though with the addition of a two-week "reading period" between the date for receiving applications and beginning interviews to ameliorate that compression. ${ }^{5}$

This hiring moratorium of the appellate bench follows more than a decade of debate among the judiciary over the clerk selection process ${ }^{6}$ and, more recently, publication of the results of an important survey of appellate judges and students of their experiences in the 1999 and 2000 clerk markets. The study - the most extensive empirical analysis extant of the market for judicial clerks-was conducted by a distinguished group of social scientists from Harvard and the University of Chicago, one of whom is an equally distinguished federal judge, Richard A. Posner, whose endorsement and participation surely enhanced the extent and frankness of judicial response to

2 See Memorandum from Chief Judge Edward R. Becker and Judge Harry T. Edwards, to Law School Deans (Mar. 11, 2002) (on file with author).

3 Indeed, the moratorium has been opposed by some judges. See James M. Rosenbaum, Federal Judges Try To Imitate OPEC, WALL ST. J., Aug. 19, 2002, at A12.

4 Letter from Jeffrey Lehman, Dean of the University of Michigan Law School, on behalf of himself and fifteen other law school deans, to the Members of the Ad Hoc Committee of Federal Appellate Judges (Apr. 3, 2002) (on file with author); see also Letter from Jeffrey S. Lehman, President, American Law Deans Association, to Members of the Ad Hoc Committee of Federal Appellate Judges (Mar. 28, 2002) (on file with author)

5 REPORT OF THE AD HOC COMMITTEE ON LAW ClERK HiRING ENDORSING A LAW CLERK HIRING PLAN FOR 2004, at http:/www.cadc.uscourts.gov/bin/lawclerk/lawclerkpdf/committee_report endorsing_2004_plan.pdf (last visited Nov. 12, 2004) [hereinafter 2004 PLAN].

6 E.g., Patricia M. Wald, Selecting Law Clerks, 89 MiCH. L. REV. 152 (1990); Alex Kozinski, Confessions of a Bad Apple, 100 YALE L.J. 1707 (1991); Louis F. Oberdorfer \& Michael N. Levy, On Clerkship Selection: A Reply to the Bad Apple, 10 I YALE L.J. 1097 (1992). 
the survey. ${ }^{7}$ The Harvard-Chicago Study concluded that the unregulated clerk market was plagued by inefficiencies: decisions were made at inefficiently early times; both judges and students expended inefficient search costs; and decisions were made based on inadequate information. More damning, the process was unfair in many respects and had degenerated into an ethics and practice creating a "frenzy of hiring [that] has cast the judiciary into disrepute ...." The authors proposed the adoption of a mandatory matching program similar to the mandatory program that, by means of a centralized computer algorithm, matches medical school graduates with hospital residencies. ${ }^{9}$ The authors recognized that many federal judges-independent and protected under the Constitution by lifetime tenure-would resist being bound by a computer matching program, and so proposed as an amendment that the match be mandatory only for those judges who wanted their clerks considered for Supreme Court clerkships. ${ }^{10}$

The Harvard-Chicago Study, in turn, follows from the work of one of its co-authors, Alvin E. Roth, who has studied problems associated with timing decisions in markets for now almost two decades." Professor Roth has investigated markets characterized by what he has termed "unraveling": 12 a form of market failure in which transactions occur at earlier, and often increasingly earlier, time periods than what would seem appropriate to maximize the infornation available to market participants. Professor Roth's wide-ranging work has identified a myriad of markets in which unraveling of this nature occurs: the choice of internships within various medical subspecialties, the allocation of athletes in professional sports leagues, medieval and modern commodity markets, and the market for judicial clerks, among others. ${ }^{13}$ Professor Roth has categorized these various markets into four separate

7 Christopher Avery, Christine Jolls, Richard A. Posner \& Alvin E. Roth, The Market for Federal Judicial Law Clerks, 68 U. CHI. L. REV. 793 (2001) [hereinafter Harvard-Chicago Study]. Avery, Jolls and Roth are from Harvard; Judge Posner of the 7 th Circuit Court of Appeals is from the University of Chicago.

$8 I d$ at 796 . The authors' discuss judicial disrepute or what they call the "disillusionment norm." Id. at 798-99, 834-40. The Harvard-Chicago Study is reviewed at length infra Part I.

9 The medical matching program is discussed at length infra Sections I.B-C.

10 Harvard-Chicago Study, supra note 7, at 875-76. The Study's proposals are discussed infra Section I.B.

11 E.g., Alvin E. Roth, The Evolution of the Labor Market for Medical Interns and Residents: A Case Study in Game Theory, 92 J. POL. ECON. 991 (1984) [hereinafter Roth, Medical Interns]; Alvin E. Roth, On the Allocation of Residents to Rural Hospitals: A General Property of Two-Sided Matching Markets, 54 ECONOMETRICA 425 (1986). Professor Roth's most general and extensive study of assortative matching markets is Alvin E. Roth \& Xiaolin Xing, Jumping the Gun: Imperfections and Institutions Related to the Timing of Market Transactions, 84 AM. ECON. REV. 992 (1994) [hereinafter Roth \& Xing].

12 To my knowledge, he coined this term-now common in the literature - to describe the early transaction phenomenon.

13 Roth \& Xing, supra note 11. The Harvard-Chicago Study reviews Roth's work on these markets. Harvard-Chicago Study, supra note 7, at 845-58. It is reviewed here infra Section I.C. 
stages according to the level of regulation of timing decisions adopted to rationalize each market, ranging from stage 1 , an unregulated market with substantial unraveling, to stage 4 , a market controlled by a centralized matching mechanism, yet with unraveling around the edges. ${ }^{14}$ Professor Roth himself has been instrumental in designing market matching programs, chiefly in medical fields, both in the United States and abroad in order to control the unraveling problem. The Harvard-Chicago Study of the market for judicial clerks adopts the Roth four-stage model in its entirety in recommending the adoption of a modified medical matching program for the selection of judicial clerks. ${ }^{15}$

Professor Roth's work today dominates the economic understanding of markets characterized by unraveling, ${ }^{16}$ just as the Harvard-Chicago Study, which builds on his work, dominates current analysis of the market for judicial clerks. This paper, however, takes a different approach. It first evaluates the market for judicial clerks-and, later, some of the other markets studied by Professor Roth-to determine what it is about those markets that generates the transaction timing phenomena that are perceived to be so troublesome. First, there exist many markets in which the timing of purchase and sale transactions differs greatly, yet where these differences are not regarded as problems. One distinctive feature of the clerk market, as well as of the many medical residency markets studied by Professor Roth, is that transactions occur in the presence of substantial uncertainty: uncertainty about the productivity of the prospective clerk or of the success of the applicant in obtaining a prestigious clerkship. Yet, there are many other markets in which transactions occur under conditions of less than complete information not characterized by unraveling. And there are many labor markets in which the same sorts of uncertainties must exist-say, the markets for high school or college graduates - which appear innocent of timing disorders.

The different approach of the paper derives from the examination of these various markets from the standpoint of the costs of continued search and the marginal value to the prospective transaction of the collection of additional information. As we shall see, the market for judicial clerks is unusual in that there exists-at least in comparison to other markets-an extremely limited range for the forms of negotiation over terms that enables other markets,

14 These stages are summarized in Roth \& Xing, supra note 11, at 993, and described infra text accompanying notes $138-167$.

15 Harvard-Chicago Study, supra note 7, at 846-47, 871-84.

16 For slightly different views, see Hao Li \& Sherwin Rosen, Unraveling in Matching Markets, 88 AM. ECON. REV. 371 (1988) (accepting the unraveling framework but explaining it as a form of insurance purchase in contexts of incomplete futures markets); and Ulrich Kamecke, Wage Formation in a Centralized Matching Market, 39 INT'L ECON. REV. 33 (1998) (attributing the need for matching in the market for medical interns to insufficiently differentiated wages). These articles are discussed infra Part II. 
including labor markets, to clear. In market contexts limited in these ways, time of commitment becomes an important available currency to clear the market. As we shall also see, many of the other markets identified by Professor Roth as suffering unraveling problems are also characterized by limitations on the terms of trade by participants in the market process. Viewed in this light, what Professor Roth has called unraveling is not a market failure, but instead reflects the operation of market processes in contexts in which other market mechanisms are suppressed. ${ }^{17}$. This approach leads to substantially different normative conclusions concerning the societal benefits of the reforms designed to eliminate unraveling.

Part I of the paper discusses the current literature on the market for judicial clerks and attempts to carefully review the helpful Harvard-Chicago Study describing and evaluating the current clerk market. Part I also discusses the broader work of Professor Roth regarding a wealth of other markets with perceived timing problems. Part $\Pi$ presents the economic analysis. Viewed as an issue of the acquisition of information until the marginal benefits of additional information are exhausted, the welfare analysis of the unraveling phenomenon reaches somewhat different conclusions. Part II then returns to the findings of the Harvard-Chicago Study and other of Professor Roth's work to reevaluate the characteristics of those markets in light of information costs and benefits. In the context of the review of the market for judicial clerks, Part II also discusses the unusual case of Yale Law School whose, recent deans have been aggressive champions for centralized control on the grounds of mitigating information deficiency Yale Law graduates purportedly suffer because of the School's policy of an ungraded first semester. Finally, Part III addresses the issue of whether, and in what way, the process that is currently characteristic of the market for judicial clerks casts the federal judiciary into disrepute. ${ }^{18}$

\section{The Current Understanding of Markets with Timing Problems}

This Part reviews historical concerns about the operation of the market for judicial clerks in the context of other markets that suffer similar unraveling problems. Section A discusses the history of the market for judicial clerks prior to the publication of the Harvard-Chicago Study. Section B reviews the Harvard-Chicago Study itself. Section C then looks more broadly at other markets that are attended by peculiarities in the timing of market transactions. Virtually all of these markets have been identified and discussed in the work of Professor Roth.

17 As also will be seen, in other markets identified by Professor Roth, time of commitment serves a related means of avoiding forms of price regulation.

18 As will be seen, various commentators on the market for clerks have made points similar to several of those of this paper. The more careful focus here, however, on information costs and on market processes aspires to pursue the analysis somewhat more rigorously. 


\section{A. The History of Disorders in the Market for Federal Judicial Clerks}

There have been concerns about the timing of transactions in the market for federal appellate judicial clerks at least since the late $1970 \mathrm{~s},{ }^{19}$ though seldom a consensus on how to reform the market. In 1978, the American Association of Law. Schools issued a set of hiring guidelines; apparently, most of the judiciary ignored them. ${ }^{20}$ Some years later, in 1983, the Judicial Conference requested that judges defer considering applications until the beginning of the student's third year of law school; again, because of non-compliance, it abandoned the effort. In 1986, Judge Stephen G. Breyer, then of the First Circuit Court of Appeals, encouraged judges to adopt April 1 of the student's second year as a beginning date; this proposal, too, failed. In 1989, Judge Breyer and Judge Edward R. Becker of the Third Circuit proposed a March 1 beginning date, circulating a letter to the entire federal appellate judiciary seeking agreement among the judges to become binding if $85 \%$ signed on. Only $75 \%$ agreed, and the effort again was dropped.

The operation of the market for clerks, however, was transformed from a subject of casual complaints and individual reform crusades into one of more widespread judicial concern in 1989 by the publication of an article in the $\mathrm{New}$ York Times by David Margolick. ${ }^{21}$ Margolick revealed to the national public the increasingly hectic character of the clerk market. His characterization was flamboyant and has been often quoted since: describing the clerk market as a "free-for-all," a "frenzied mating ritual," quoting a Stanford student, describing appellate judges as "behaving like 6-year olds."

Margolick's article spurred intensified reform efforts. A group of judges, led again by Judges Breyer and Becker, now joined by Judge James Oakes of the Second Circuit and Judge Patricia M. Wald of the D.C. Circuit, obtained an agreement from judges in ten of the thirteen federal circuits not to issue offers during the 1990 clerkship market until May 1 at 12:00 p.m. EST and to allow all offers to remain open for twenty-four hours. According to Judge Wald, describing the market that year, though there were some defections by judges making early offers, most judges initially complied. ${ }^{23}$ Yet as judges perceived that their colleagues in the three circuits which had not agreed to the deadline were gaining an advantage, defections increased. Judge Wald explains, "[i]n

19 The literature describing the clerk market focuses on fedcral clerks, chiefly federal appellate clerks. Thus, it is not known whether markets for state appellate court clerks or clerks in specialized courts, such as the Tax Court, suffer similar timing problems.

20 This history of reform efforts through 1994 is taken from Edward R. Becker et al., The Federal Judicial Law Clerk Hiring Problem and the Modest March 1 Solution, 104 YALE L.J. 207 (1994).

21 David Margolick, At the Bar: Annual Race for Clerks Becomes a Mad Dash, N.Y. TIMES, Mar. 17, 1989, at B4.

22 Id.

23 Wald, supra note 6 , at 158. 
some cases, complying judges rationalized that, in meeting the offer of a noncomplying judge, they were not violating the agreement.", Then, "[i]n early April, one of the major circuits withdrew . . ..25 As the May 1 deadline approached, matters became worse. Some judges enlisted their clerks to make early calls to applicants. On the morning of May 1, "[a] few judges weakened . . . and made calls ahead of the deadline. This, in turn, provoked the students to call other judges they preferred before the noon deadline, ..." leading to a "destabilizing flurry of pre-deadline transactions." 26 The May 1 experiment was dropped the next year.

Margolick's scathing article and the failure of the 1990 reform generated serious judicial analysis of the market. ${ }^{28}$ Judge Wald, one of the leaders of the 1990 reform, published an important article in the Michigan Law Review addressing complaints "that the clerkship selection process is undignified, even demeaning." "Wald began with a puzzle: why is it so difficult "to conduct a dignified, collegial, efficient law clerk selection process?" ${ }^{30}$ Since the judge "has no need or ability to dicker on salary or hours or perks, one would expect the process to go quickly and smoothly." Instead, the process is characterized by "covert maneuvering by judges and applicants" and "[j]udges... sometimes are unseemly in their pursuit.",32 Conversely, but equally, "[c]lerk candidates . . . are not themselves without guile; they learn quickly to hedge, to answer some calls earlier than others, to avoid some calls altogether, and to solicit time in which to seek competing offers.",33

Judge Wald's explanation was that the significance of clerk quality to the judge led to vigorous competition for superior clerks. The judge-clerk relationship was "intense and mutually dependent." ${ }^{34}$ The judge is constrained by a small staff that cannot be supplemented, and judges rarely fire clerks. "If for any reason one of her clerks proves significantly deficient, she, or the other clerks, must take up the slack .... [A]n excellent versus a mediocre team of clerks makes a huge difference in the judge's daily life and in her work

24 Id.

$25 I d$.

26 Id. at 159.

27 The 1990 reform effort is also described in Becker et al., supra note 20, at 210-11.

28 There had been earlier judicial writings on the character of the clerk market. In a 1986 article, Judge Mikva of the D.C. Circuit Court of Appeals described the "timing for clerk selection" as "awful," characterized some of his colleagues as "Sooners," and cracked that some were "frequenting maternity wards to make sure they get the 'best' clerks." Abner J. Mikva, Judicial Clerkships: A Judge's View, 36 J. LEGAL EDUC. 150, 152 (1986).

29 Wald, supra note 6, at 156.

$30 \quad$ Id. at $\mathbf{I} 52$.

$31 \quad I d$.

$32 \quad I d$ at 152,156

33 Id. at 156.

$34 \quad$ Id. at 153. 
product. ${ }^{, 35}$ Moreover, "[a] judge's reputation among his own colleagues may in part reflect his ability to garner the most highly-credentialed clerks . ...,36 As a consequence, both judges and clerks had succumbed to a set of strategic tactics to maximize their opportunities in the market. ${ }^{37}$ Judge Wald recommended the adoption of a matching program much like the medical match for hospital residencies. ${ }^{38}$ Though a matching program would not solve all problems, it "deserves at least a fair trial.,"39

Judge Wald's article generated an immediate response from Judge Alex Kozinski of the Ninth Circuit. Kozinski admitted that the current operation of the market was unfortunate in some respects, but generally defended the high level of judicial rivalry over clerks as a "normal, healthy competitive market process where the parties bargain with each other on roughly equal footing." Judge Kozinski saw the various proposed reforms as limiting "the means by which less-favored clerkships can compete for desirable applicants. ". ${ }^{, 41}$ According to Kozinski,

not all clerkships are created equal ... [p]restige counts. Some circuits, the

D.C. Circuit in particular, tend to draw a disproportionate share of the nation's top applicants. Seniority matters. Judges with many years on the bench naturally have an advantage over upstarts like me who have to work hard at achieving a national reputation.

Early offers of positions serve as "a very important bargaining tool for judges competing for the most gifted clerkship candidates. ${ }^{, 43}$ Like Judge Wald, Judge Kozinski noted that a judge could not negotiate on salary or hours or perquisites. ${ }^{44}$ But a judge can dicker on "the possibility of ending the [student's ] agony by accepting an early offer." there were natural limits to the starting time of the market: "the breakpoint for many judges ... . comes around February or March of a student's second year of law school" because by then third-semester grades are available, papers will have been written under faculty supervision, and law review board elections held ${ }^{46}$ Judge Kozinski admitted that there were some problems with the market: he accepted that tactics such as exploding offers or providing adverse

38 Id. at $160-63$.

39 Id. at 163.

40 Kozinski, supra note 6, at 1714.

41 Id. at 1719.

42 Id.

43 Id.

44 Id. at 1720.

$45 \quad I d$.

$46 I d$ at 1710 
information about another judge were "undignified" and "improper." recommended that the only reform needed was to make the process more open by finding "better ways to detect and punish perfidy, strong-arm tactics and other unethical behavior," acts by judges.

Judge Kozinski's article was controversial, and it led to a response by the distinguished D.C. District Court Judge Louis F. Oberdorfer and Michael N. Levy, one of Judge Oberdorfer's former clerks: ${ }^{49}$ Judge Oberdorfer believed that the unruly clerk market that Kozinski was defending had effects that were deeply damaging to society:

Federal judges are sworn to dispense "equal justice to the poor and to the rich." They are supposed to go about this awesome task deliberately, and with a dignity that will inspire and maintain firm public confidence in the decisions that they make and the way that they make them. The present method used by federal judges to select their law clerks unnecessarily jeopardizes that confidence. ${ }^{50}$

The principal problem with the market according to Judge Oberdorfer was the lack of information available to the parties that resulted from the competition over early offers. He compared the market for clerks to other entrylevel legal markets:

The federal government subjects attorney applicants to searching inquiries by the Federal Bureau of Investigation. Law schools screen faculty prospects with exquisite care and intense faculty debate. Law firms hire associates based on their records of accomplishment after two full years of law school. They prefer to make job offers after personally observing students' work for an entire summer. Partnership decisions are made only after seven or more years of working together.

In contrast, at the time the clerkship offer is extended, judges and clerks "know practically nothing about each other." Rejecting Judge Kozinski's free market analogy, Judge Oberdorfer strongly recommended adoption of the medical matching program, comparing it to the operation of the New York Stock Exchange. "A truly rational and efficient free market requires full and free exchange of information and uninhibited choice of competing products or services." 54

Judge Oberdorfer's call for adoption of a matching program proved unsuccessful. According to one report, the market in 1991 "was as frenetic as

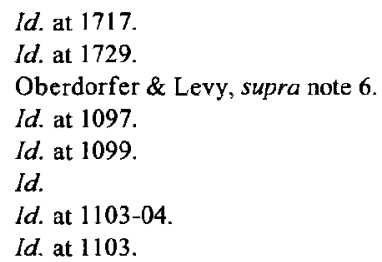


1989 had been. The next year was even worse." ${ }^{55}$ In 1993, another reform was attempted. Judges Breyer and Becker resumed their efforts with the judiciary. ${ }^{56}$ Guido Calabresi, then Dean of Yale Law School, wrote to every law school dean in the nation seeking endorsement of a March 1 interview date. ${ }^{57}$ A large number endorsed the proposal leading the Judicial Conference to establish March 1 as the benchmark date for the beginning of clerkship interviews, to begin March 1, 1994. ${ }^{58}$ Shortly after the first year of the reform, Judges Becker, Breyer and now-Judge Calabresi, since appointed to the Second Circuit, published an influential article supporting the "March 1 Solution." Although they conceded that some judges had failed to comply (the date was only a benchmark, and not binding), they claimed that most judges had recognized the benefits of delaying interviews, and the March 1 date deserved compliance in the future. 59 There were "several problems with the existing 'free market' in clerkships-all of which were substantially alleviated by the March 1 reform.,, 60 Interviews at earlier dates interfere with classes, deny students "the opportunity to adjust to the rigors of law school," and prevent students "from focusing their interests in law before deciding whether to apply for a clerkship." considered other reforms. The medical match model, endorsed by Judges Wald and Oberdorfer, was attractive, but its principal problem was that judges found it "unacceptable." 62 In a 1989 survey, only one-third approved it. ${ }^{63}$ Still, Kozinski's free-market solution was equally unacceptable. ${ }^{64}$

There is little systematic evidence of markets for clerks in the years following 1994, but it appears that the Judicial Conference's benchmark proved unsustainable. The Conference abandoned the benchmark in 1998, acknowledging that "it has become apparent that it is not universally followed and, therefore, is not an accurate reflection of the practice in the courts. Moreover, there is no consensus within the judiciary as to whether any alternate standardized policy could be more successful in improving the law clerk hiring process." ${ }^{65}$ A year later, in September 1999, most prominent law schools withdrew efforts to constrain the time at which faculty recommendation letters could be sent. ${ }^{66}$ The clerkship market continued without regulation.

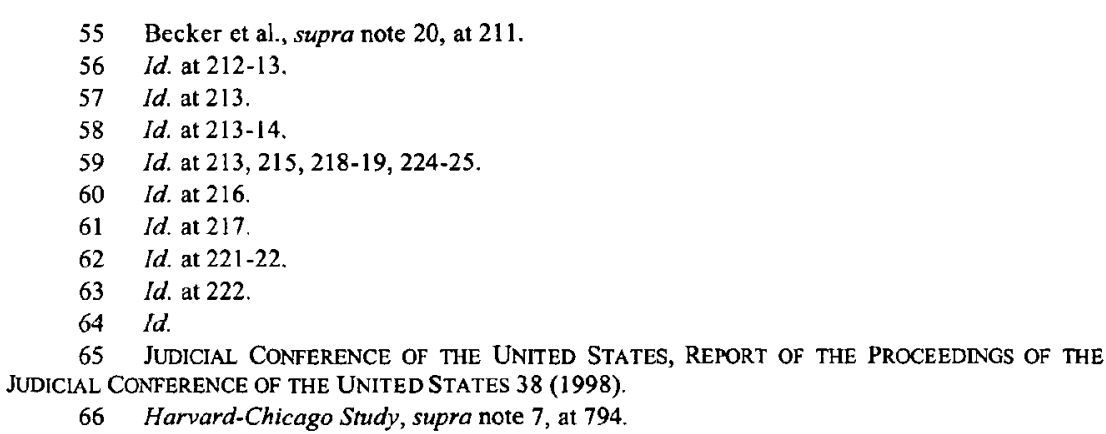




\section{B. The Harvard-Chicago Analysis of the Market}

Concerns about the operation of the clerkship market, however, did not diminish. As previously mentioned, in 2001 a group of social scientists from Harvard and the University of Chicago published an economic analysis of the clerkship market, bolstered by the results of an extensive survey they conducted of appellate judges, Supreme Court judges, and students at leading law schools concerning its operation. The analysis built upon the work of Professor Roth, one of the Harvard-Chicago Study's co-authors, who has pioneered research into markets characterized by unraveling.

\section{The Normative Framework}

The authors first set forth a normative framework for analysis. They sought to determine whether the market for clerks 1) cast disrepute on the judiciary; 2) was efficient, which they defined as providing for "the ability of market participants to consider and compare the alternatives available in the marketplace;" and 3) was perceived to operate fairly. ${ }^{67}$ They found that the clerkship market failed in every respect. That it contributed to disrepute of the judiciary was obvious. There were many sources of inefficiency. And there were many features of the market that appeared substantively unfair.

1) Disrepute of the judiciary. Citing the Margolick article and the various judicial writings criticizing the clerkship market, the Study accepted entirely that the current operation of the market harmed the image of the judiciary. "A system in which hiring occurred in an orderly and respectable manner would be preferable to a system ..." in which "judges are jockeying for position and trying to outmancuver one another in the competition for the best law clerks." ${ }^{68}$

2) Efficiency. There were many ways in which the clerkship market violated the authors' efficiency norm: offers were made at inefficiently early times in terms of the acquisition of information.

In a market with limited numbers of buyers and sellers, parties are not able to gather information about multiple options and then act on that information to seek out their most preferred alternatives. Choices must be made from a very small set of alternatives and in a very compressed period. Decisions must be reached on the basis of extremely limited information. And if participants try to refine their information, they may not be able to do so in a timely enough fashion, since time spent in ultimately fruitless courtship (for

67 Id. at $798-805$.

$68 I d$. at 799. The authors accepted the colorful characterization by one circuit court judge, Alfred E. Goodwin of the Ninth Circuit, Becker et al., supra note 20, at $210 \mathrm{n} .8$, that the clerk market resembled a calf scramble, an occasional Western rodeo event in which youngsters chase calves let loose in an arena. Harvard-Chicago Study, supra note 7, at 799. As we shall see, the analogy is not exactly apposite. See infra note 201 
instance, in making an offer that is subsequently refused) means that other candidates will have matched and left the market. All of these features have the potential to introduce substantial inefficiency. ${ }^{69}$

Illustrative of the point, the market compelled judges to make decisions chiefly on the basis of first-year grades, but - based on a review of grades at Harvard Law School-there were differences between students' first-year and second-year records, suggesting the likelihood of subsequent judicial error. ${ }^{70}$ The market was additionally inefficient because both students and judges expended excessive amounts in search costs because of the need for multiple interviews. The authors conceded that early offers provided an insurance-like benefit to risk-averse candidates. ${ }^{71}$ But these benefits were more than offset by efficiency losses from mismatches that occurred because of inadequate information about potential choices at the time of the market transaction. "The problem with such early hiring is that [at the time of hire] two-thirds of the information about the student's academic record in law school, plus virtually all of the information about the student's legal writing, which typically is done in the second and third years, is missing."

The lack of information created substantial risks of mismatches between judges and students. ${ }^{73}$

3) Fairness. The authors argued that, important to the evaluation of the clerkship market, was the perception of fairness in the process itself. The substantial dissatisfaction with the market of both judges and students suggested problems in this regard, principally again deriving from the difficulty of obtaining information about candidates. The authors suggested that favoritism by judges - in their words, "personal well-connectedness"-may influence choices which could be perceived as being unfair. ${ }^{74}$

\section{Empirical Findings}

The authors sought to test these normative hypotheses by surveying all federal appellate judges, Justices of the Supreme Court, and samples of law

69 Harvard-Chicago Study, supra note 7, at 801.

70 Id. at $802-03$.

71 Id. at 803-04 (citing Li \& Rosen, supra note 11. This article is discussed infra note 179.

72 Harvard-Chicago Study, supra note 7, at 801-02.

$73 \mathrm{Id}$. In an interesting passage, the authors discussed how to evaluate whether the mismatches that occur in the clerkship market affect judicial output. They surmised that, if judicial output is merely an additive function of a judge's and a clerk's abilities, mismatches will have no effect (i.e., the sum total of output will be the same regardless of matching); if the clerk's abilities provide more benefit to less able judges, mismatches increase output; but, if output is a multiplicative function of a clerk's and a judge's abilities, mismatches reduce output. Id. at 804 . The authors (with admirable honesty) confessed that they could not confidently define the determinants of judicial output, and so discarded the issue: "For this reason, we give primary emphasis below to the criterion of maximizing the satisfaction of judges and clerks with the match." Id.

$74 \quad$ Id . at 805. 
school students in 1999 and $2000 .^{75}$ The results of the surveys confirmed the authors' hypotheses. The survey findings add substantial depth to the understanding of the operation of the clerkship market. According to the authors, the unregulated clerkship market comprises four steps: (1) interviews lead quickly to offers; 2) offers require quick responses; 3) responses are acceptances; and 4) subsequent interviews are canceled. ${ }^{76}$ This process established to the authors that the clerkship market was seriously inefficient. ${ }^{77}$

1) Interviews lead quickly to offers. The Study found that, in $34 \%$ of interviews, appellate judges extended offers immediately at the end of the interview. ${ }^{78}$ In a cumulative $57 \%$ of interviews, offers were extended within two days. $^{79}$ Of these offers, $36 \%$ came from the first judge the student interviewed; a cumulative $59 \%$ came from the first or second judge interviewed. ${ }^{80}$

2) Offers require quick responses. The Study found that "this is not a market in which students collect a substantial number of offers and then make their decisions." 81 For $42 \%$ of offers, students accepted them immediately upon receipt; in a cumulative $71 \%$, students accepted offers within two days. ${ }^{82}$ Here the Study documented the short-fuse or exploding offer problem that had been described in earlier reports. Many of these reports are anecdotal: one judge extended the offer for only fifteen minutes, another required an immediate answer, and the like. ${ }^{83}$ The Study described this problem as systemic: during the 2000 market on an aggregate basis, $25 \%$ of judges required answers with twenty-four hours; a cumulative $38 \%$, within forty-eight hours; and a cumulative $68 \%$, within a week. ${ }^{84}$ The expectation that applicants would respond quickly to offers meant that there were advantages to clerks to arranging their interviews strategically. The Study found that "many students limit the judges to whom they apply to avoid being paired off early with a less preferred judge., ${ }^{, 85}$ One student responded to the 1999 survey confessing: "[t]hroughout the process I... strategize[d] and manipulate[d] ... not

75 Id. at 807-12. The authors report very little from the survey of the Supreme Court: only that members of the Court believe that the appellate clerkship market is a "mess," but that the Supreme Court market is not affected because the Justices receive many more applications from fully qualified candidates than there are positions. Id. at 876-77. The authors infer from this response that the Supreme Court might be amenable to compelling a medical match program in the appellate market as a condition of application for a Supreme Court clerkship. Id. The authors' match proposal is discussed infra text accompanying notes 116-124.

76 Harvard-Chicago Study, supra note 7, at 813.

77 See id. at 813-34.

78 Id. at 814 tbl.1.

79 See id.

80 See id. at 814 tbl.2.

81 Id. at 817.

82 Id. at 817 tbl.5.

83 Id. at 818 tbl.7.

84 Id. at 818 tbl.6.

85 Id. at 813. 
answering the telephone for fear of being trapped into a less-than-ideal interview early on, and trying to arrange interviews strategically . . ., ,86

But judges behaved strategically as well in scheduling interviews and requiring quick responses, in some cases despite earlier promises to a candidate to keep the process open to allow the candidate to interview other judges. ${ }^{87}$

3) Responses are generally acceptances. The Study found that $73 \%$ of students accepted the first offer that they received. ${ }^{88}$ Perhaps as a result, $68 \%$ of students only received one offer; ${ }^{89}$ a cumulative $93 \%$ received only two offers. ${ }^{90}$ These findings demonstrated to the authors that "the law clerk market does not appear to be one in which students have the opportunity to consider a range of options before making their decisions."91 The Study also found, more alarmingly, that the first offer was the "first-choice position" of only $34 \%$ of students and not the first-choice of $66 \% .^{92}$ Of that $66 \%$, more than half, $58 \%$, had nonetheless accepted it. ${ }^{93}$ Thus, in aggregate, $38 \%$ of responding students accepted offers from other than their first-choice judge. ${ }^{94}$ Many of the students provided explanations for their decisions. As the authors characterize them, they reflect "the strong student aversion to sacrificing a 'bird in the hand' for uncertain prospects down the road." 95

4) Subsequent interviews are canceled. The Study found that $79 \%$ of judges during the 1999 market and 66\% during 2000 had subsequentlyscheduled interviews canceled by students. ${ }^{96}$ The authors interpret this finding, along with the finding that students receive early offers from "non-top-choice judges" as demonstrating that "applicants are missing the chance to consider what might be more preferred alternatives.",97

The authors conclude that these various findings demonstrate the inefficient operation of the clerkship market. Perhaps the clearest finding in this regard is the substantial number (38\%) of students who accept offers from other than their first-choice judge. The authors describe the other findings, however, as also providing confirmation of inefficiency. The early offers, early acceptances, and cancellations of subsequent interviews show that the clerkship

$86 I d$. at 821 (alteration in original).

87 Id. at $819-20$.

88 Id. at 821 tbl.8.

89 That is, at least $5 \%$ received a second offer after accepting the first offer.

90 Id.

91 Id. at 820

92 Id. at 823 , tbl. 9 .

93 Id.

94 Derived by author. Note that the Harvard-Chicago Study did not inquire of the $27 \%$ who declined their first offer from a judge not their first choice whether they ever received an offer from their first-choice judge.

95 Harvard-Chicago Study, supra note 7 , at 824.

96 Id. at 826,827 , tbl. 11.

$97 \quad I d$ at 826. 
market is not one in which both clerks and judges are presented a wide range of alternatives before making their choices. ${ }^{98}$ And the problems with the market are accelerating. The Study found that $57 \%$ of judges in 2000 were conducting interviews and extending offers earlier than they had in the preceding year. ${ }^{99}$

Finally, the Study also uncovered data that suggested the clerkship market operated in a way that participants in the market could regard as being substantively unfair. ${ }^{100}$ Because of the "frenzied manner and early timing of hiring," some judges were led to rely on "various forms of personal wellconnectedness" in selecting clerks. ${ }^{101}$ As examples, some judges (or their clerks) seek information from an applicant's current classmates (i.e., a classmate also applying to the judge) or from recent law school graduates who are clerks. ${ }^{102}$ In addition, some faculty members are given a position as a "clerkship broker," encouraging connections between a judge and a student beyond simply submitting a general recommendation. ${ }^{103}$ The Study uncovered "various [other] forms of social well-connectedness, including connections with friends of a judge or a judge's former clerks." ${ }^{104}$ Although the authors avoided taking the position that these forms of connections were substantively unfair, ${ }^{105}$ they did show that some participants regarded them as unfair. ${ }^{106}$

The Harvard-Chicago Study, as mentioned, is the most thorough and extensive examination of the market for judicial clerks that has yet been conducted. As certainly might be expected, the authors interpreted the Study's findings to support reform of the clerkship market. Prior to setting forth reform proposals, however, the authors situated the market for judicial clerks in the context of other markets with timing peculiarities, building on the work of one of them, Professor Alvin E. Roth. ${ }^{107}$ I will discuss Professor Roth's work in the next Section. It should be remembered, however, that the authors' reform proposals derive from a far greater range of studies of markets with timing problems than only the clerkship market. As mentioned, and as will be discussed more extensively next, Professor Roth categorizes markets with timing problems into four stages: stage 1 , an unregulated market with unraveling; stage 2, markets with regulations specifying offer times; stage 3, markets with centralized market clearing procedures (such as the medical

98 See id. at 813.

$99 \quad I d$. at 831 tbl.13.

100 The Harvard-Chicago Study, of course, also uncovered many responses from judges and students complaining about the lack of order and dignity in the process. See $i d$. at 835 tbl.15; 838 40 tbls.17-1, 17-2.

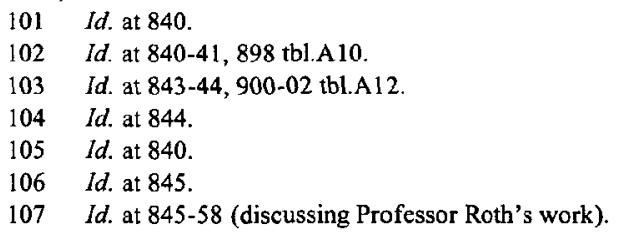


match); and stage 4, markets with centralized mechanisms, but in which unraveling occurs prior to operation of the centralized market-matching mechanism. Stage 4 markets require even greater regulation beyond the introduction of the matching system. As we shall see, Professor Roth's fourstage analysis informs the authors' recommendations for reform of the clerkship market.

\section{The Harvard-Chicago Recommendations}

Following the report of the Study's findings, the authors considered four basic forms that the clerkship market might take: a) an unregulated free market; b) a market with established start dates; c) a market determined by a mandatory medical match mechanism; and d) a market with a modified medical match mechanism, applicable only to judges who want their clerks to be considered for Supreme Court clerkships.

\section{a. Leave the Market Unregulated}

The authors rejected maintenance of an unregulated free market (Professor Roth's stage 1). Without regulation, "[h] iring will continue to occur in a frenzied manner and is likely to move back even further in the student's law school career, so that even less information is available." 108 Further information-such as when specific judges expect to begin hiring-would aid such a market, but the authors viewed the prognosis of such a market as "grim.,"109

\section{b. Set Fixed Start Dates for Market Transactions ${ }^{110}$}

The authors rejected further attempts to reform the market by setting fixed dates for interviews and offers (Professor Roth's stage 2). According to the authors, where these reforms have been introduced in the clerkship market, they failed; they have also been attempted in markets for medical residencies, college football bowls, and clinical psychology positions, among others, equally failing. (The Harvard-Chicago Study, of course, was published prior to the appellate moratorium of 2002-04.) Even where start dates are complied with, they create serious problems of transaction congestion because market transactions are compressed into a much shorter time period. More generally, however, there are strong incentives for participants to defect from the start dates in order to gain an advantage on their competitors. The authors consider

108 Id. at 861 .

109 Id. at $861-62$.

110 See id. at 862-68, for the Harvard-Chicago Study discussion summarized here. 
a palliative: "limiting the information available to judges prior to the start date. Making it more difficult for judges to gather information will impede their ability to move early ...." But the authors despair that even this reform is likely to fail; moreover, even if successful, it will not solve the insuperable problem of transaction congestion at the start dates themselves. Again, to the authors, the prognosis of a market constrained only by start dates is "grim."

\section{c. Adopt a Centralized Transaction Mechanism Like the Medical Match $^{113}$}

The medical match (Professor Roth's stage 3) brings together students about to graduate from medical school applying for a wide range of medical residencies with the hospitals that manage residency programs. Following interviews, both applicants and hospitals register for the match and submit rank-ordered lists of preferences-the applicants for preferred hospitals; the hospitals for preferred applicants. On a fixed date, a centralized computer program matches these preferences: i.e., if a hospital's first choice applicant has listed the hospital as its first choice, they are matched; if a hospital's second choice applicant has not been matched with his or her first choice, but has listed the hospital as the second choice, they are matched; and so on.

The medical match model deals with the problem of transaction congestion at the hiring date but, according to the authors, engenders still other problems. The most significant is that, despite the matching program, parties face incentives to cheat on the match by entering agreements prior to the date of the match-open or tacit-that inform the rank-orderings they submit to the match. According to the authors, it is estimated that $10 \%$ to $15 \%$ of medical students (and of course the corresponding hospitals) cheat on the medical residency match in this way. ${ }^{114}$ The authors are concerned that, given the much smaller market for judicial clerks, cheating is likely to be more prevalent which would make adoption alone of a match "highly problematic."115

\section{d. Adopt a Modified Medical Match Program ${ }^{116}$}

Finally, the authors recommended adoption of what they call a modified medical match (Professor Roth's stage 4). As discussed, the pure medical match possesses flaws because it cannot itself prohibit cheating. In addition, as the authors frankly admit, many judges would object to it. Their surveys of

113 See id. at 868-871, for the Harvard-Chicago Study discussion summarized here.

$114 \quad I d$ at 870.

115 Id. at $870-71$

116 See id. at $871-77,883-84$, for the Harvard-Chicago Study discussion summarized here. 
appellate judges uncovered many who, like Judge Kozinski, endorsed maintaining the market without regulation, either because they believed themselves to be effective in competition or were unaffected by the congestion and early hiring pressures objected to by others. ${ }^{117}$ These judges would oppose adoption of a matching program, and are of sufficient number to defeat such a proposal. $^{118}$

In response to this problem, the authors proposed a modified medical match according to which participation in the match would only be mandatory for those judges who want their clerks to be subsequently considered for Supreme Court clerkships. The logic of their proposal is this: According to the authors there are two groups of judges: "those who are engendering the problems in the market" by early interviewing and early offers; and the rest of the judges who perceive no problems with the market because they proceed more leisurely in hiring clerks. ${ }^{119}$ The first set, those causing the problems, are judges who are more likely to want the prestige that attends "feeding" clerks to the Supreme Court. Making the match mandatory for those judges would, in essence, segregate the miscreants from the rest of the clerkship market. ${ }^{120}$ The other attraction of the proposal is that, however limited the authority of the Judicial Conference or, surely, of ad hoc committees of judges, the Supreme Court possesses the authority over the judicial system to order introduction of a mandatory match for applicants (and the judges who want them as appellate clerks) who want to be later considered for Supreme Court clerkships. ${ }^{121}$

Still, as explained above, the authors fear that even matching programs may be attended by cheating: informal arrangements confirming preferences prior to the submission of rank order listings to the match mechanism (Professor Roth's stage 4). The authors proposed dealing with this problem by introducing "a small degree of randomization in the match to destabilize the informal understandings." 122 More precisely, the matching program will prohibit judges and applicants from entering agreements or understandings with regard to the preference list they submit to the match. Yet, if some threshold of non-compliance is detected, according to the authors, say, $1 \%$ of candidates, "then it could be announced that $5 \%$ (for example) of applicants would have

117 Id. at 873-75 tbl.22.

118 Again, in a 1989 survey of appellate judges, only one-third approved adoption of a medical matching program. Becker et al., supra note 20, at 222.

119 Harvard-Chicago Study, supra note 7, at 872.

$120 \quad$ Id. at $871-84$.

121 As mentioned, supra note 75, the chief finding that the authors report from their survey of Supreme Court Justices is that the Justices don't like the appearance of the appellate market, but feel they have no particular problems finding well-qualified clerks. The authors interpret this absence of concern as opening the possibility for the Supreme Court to mandate a match on the grounds that the Supreme Court will receive able applications, match or not. Harvard-Chicago Study, supra note 7 , at $876-77$.

$122 \quad$ Id. at 883. 
their first and second choices randomized in the centralized match." ${ }^{23}$ This penalty would deter informal agreements directly, and also provide grounds for one party, reluctant to enter an informal agreement, to rebuff the invitation of another party to cheat. ${ }^{124}$

To date, the recommendations of the Harvard-Chicago Study have not been adopted. Nevertheless, as mentioned in the introduction, following the publication of the Harvard-Chicago Study in 2001, fervor to reform the clerkship market was rekindled. An ad hoc committee of federal judges succeeded in securing an agreement among the appellate judiciary upon a oneyear moratorium on the submission of applications and recommendations until after Labor Day which went into effect in 2003 and has recently been extended to 2004. As mentioned, the authors of the Harvard-Chicago Study predicted substantial transaction congestion following such a start date that they believed would outweigh the gains from the existence of greater information about applicants. ${ }^{125}$ Many judges appear to have complained about the congestion problem in 2003 which led the Ad Hoc Committee to propose for 2004 a twoweek "reading period" between the receipt of applications and the beginning of interviews. ${ }^{126}$

\section{The Broader Context of Market Unraveling}

As mentioned, both the Harvard-Chicago Study analysis of unraveling in the market for judicial clerks and the Study's reform recommendations were informed by the analysis of unraveling in a wide range of other markets by one of the Study's co-authors, Professor Roth. ${ }^{127}$ In an extensive series of papers published over the past two decades, Professor Roth has demonstrated that a diverse set of markets, ancient and modern, have suffered problems in the timing of market transactions. ${ }^{128}$ The vast majority of the markets that Professor Roth identifies involve entry-level professionals, though he presents many other examples including medieval commodity markets.

According to Professor Roth, the timing problems in these markets lead to "potentially large losses of efficiency. . . In virtually all of these markets, the problems originate with the incentives that some market participants have to try to 'jump the gun,' and arrange transactions just a little earlier than their

123 Id.

$124 I d$.

125 Id. at 868 .

126 See 2004 PLAN, supra note 5.

127 The Harvard-Chicago Study reproduces and discusses Professor Roth's findings. Harvard-Chicago Study, supra note 7, at 845-58.

128 His central paper, from which most of this discussion derives, is Roth \& Xing, supra note 
competitors." ${ }^{129}$ In most of the markets, the unraveling of transaction times "often occurred despite the vigorous efforts of market participants to halt it due to the costs it imposed ....", 130 These costs are the "costs of having to hire in anticipation of uncertain future need, costs of potential mismatches caused by the uncertainty of employees' qualifications before they had completed their training, and the increased costs of search and loss of liquidity as the variance in times of appointment increased."131

Professor Roth presents a simple model illustrating the problem. Imagine that there is some final period $T$ (such as graduation from school) and earlier periods, $T-1, T-2$, and the like, at which earlier transactions may be made. The "worker $w$ at time $T$ is an agent with certain attributes, but . . at time $T$ - 1 , before the attributes are known, the workers can be identified only as members of [a] set... [possessing] a probability distribution ... over possible attributes." 132 By definition, transaction times will "unravel whenever it is not an equilibrium for all contracts ... to be signed at time $T$,"133 According to the Roth analysis, there are three principal reasons that this unraveling might occur:

1) Instability in matching at time $T$ (e.g., congestion in the last moments of a uniform timing regime, or an unstable centralized market-clearing mechanism). "If the uncertainty at time $T-1$ is sufficiently small compared to the cost of being mismatched, then such agents have an incentive to make their transactions early to avoid the unstable institutions at time $T . " 134$

2) Risk preference by some participants. If "some participants . . . prefer [ ] arrang[ing] their transactions before some uncertainties are resolved," they may enter transactions at time $T-1$, "forc[ing] other participants to move early also.",135

3) Differential market power as between time $T$ and time $T-1$, i.e., where a worker believes that he or she would be in a superior competitive position at time $T-1$ than at time $T$, given different competing participants in the market. ${ }^{136}$

Note that the unraveling on account of participant risk preference or differential market power can occur despite the existence of a stable marketclearing mechanism that optimally matches participants at time $T$. Note also

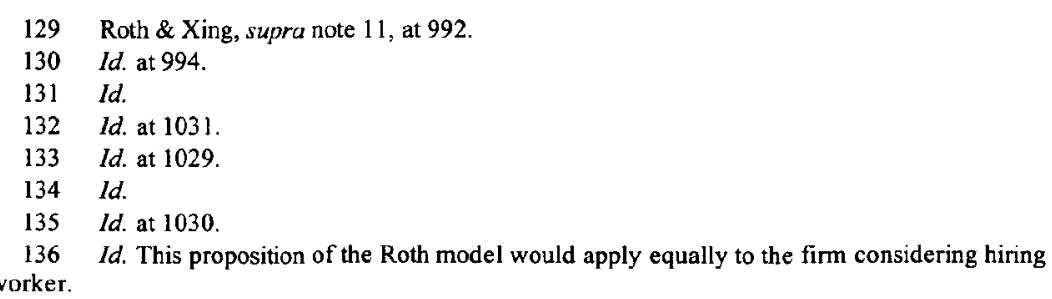


that, in the Roth model, the concept of optimal match consists of an optimal ordinal match as between workers and firms. An ordinal match is one in which a worker is matched with its first-choice firm where that worker was the firstchoice of the firm; subsequently, second-choices are matched with secondchoices (because their respective first-choices were otherwise matched with their first-choice matches), and so on. Given this formulation of the model, it is obvious why Professor Roth and his followers so strongly advocate the introduction of centralized matching mechanisms, such as the medical residency match, since ordinal matching is exactly what those mechanisms can accomplish. Similarly, given that the objective is to devise a mechanism to generate an optimal ordinal match, it is evident why Professor Roth is critical of activities that lead to earlier agreements, because they render moot the operation of the subsequent computer match. Professor Roth views such activities as unfortunate because any agreement reached outside the operation of the centralized matching mechanism introduces a risk of sub-optimality. ${ }^{137}$

Professor Roth categorizes markets affected by unraveling into four separate stages. To Professor Roth, a stage 1 market

begins when the market comes into being... and the relatively few transactions are made without overt timing problems. By the middle of stage 1 the market has grown, and some appointments are being made rather early, with some participants finding that they do not have as wide a range of choices as they would like.... The trade journals start to be full of exhortations urging employers to wait until the traditional time to make offers, or at least not to make them any earlier next year than this year. Toward the end of stage 1 , the rate of unraveling accelerates, until sometimes quite suddenly offers are being made so early that there are serious difficulties in distinguishing among the candidates.... As stage 1 ends, influential market participants are engaged in a vigorous debate about what can and should be done. From beginning to end, stage 1 may have covered a period of more than fifty years, or fewer than ten.

A stage 2 market, in contrast, is one in which there are attempts to establish uniform dates before which offers should not be made and sometimes limits imposed on interviews. ${ }^{139}$ Yet,

[e]ven when uniform dates are successfully established and maintained, the market often experiences a great deal of congestion and chaotic behavior, as the deadline for accepting or rejecting offers grows near.... Firms whose first-choice candidates reject them may now find that their next dozen candidates have already accepted offers, and candidates may receive preferred offers moments after making a verbal commitment to accept an earlier offer.... [I] $n$ the aftermath, many firms and candidates have just missed making

137 This point explains the concerns of the authors of the Harvard-Chicago Study about cheating on their recommended appellate match which they hoped to deter by randomizing portions of the match. See supra text accompanying notes 122-124.

138 Roth \& Xing, supra note 11, at 996.

139 Id. 
connections they would have preferred. The result is that the following year witnesses a resurgence of strategic behaviors designed to avoid being caught short at the end of the market.... While some markets have persisted for many seasons in this fashion, systems of formalized dates are often abandoned, with the market either reverting to stage 1 , or moving on to stage 3 .

Stage 3 involves the creation of a centralized market-clearing procedure. ${ }^{141}$ Interviews remain decentralized, but all offers and acceptances occur through a centralized mechanism, rather than by the parties directly. ${ }^{142}$ According to Professor Roth, centralized mechanisms are not always successful; sometimes, the mechanism is abandoned and the market reverts to stage $1 .{ }^{143}$ In other contexts, "stage 3 may be the final stage in the market's evolution. However some of these markets go on to stage $4 ., 144$

Finally, a stage 4 market is one with a centralized matching mechanism in place, but where unraveling occurs in periods before operation of the mechanism. ${ }^{145}$ In these markets, despite the existence of the centralized mechanism, "the unraveling has often taken the form of recruiting students for summer internships (or in the case of some medical specialties for 'audition electives'), which amount to extensive interviewing opportunities in which the student spends a period of weeks or even months at the firm."146

Here, the unraveling does not eliminate all of the benefits of the centralized match, because the match can still facilitate transactions where firms need to hire applicants who did not serve the internship. ${ }^{147}$ This continued benefit of the centralized mechanism distinguishes stage 4 unraveling from that in stage 1 , where all transactions were decentralized.

Professor Roth presents many examples of markets characteristic of each of his four stages.

\section{Stage 1 Markets}

The best example of a stage 1 market, characterized by substantial unraveling, is the market for American federal judicial clerks, extensively discussed by Professor Roth. ${ }^{149}$ A second example is entry-level hiring in the

$\begin{array}{ll}140 & I d . \\ 141 & I d . \text { at } 996-97 . \\ 142 & I d . \text { at } 997 . \\ 143 & I d . \\ 144 & I d . \\ 145 & I d . \\ 146 & I d . \\ 147 & I d . \\ 148 & I d . \\ 149 & I d . \text { at } 1001-04 .\end{array}$


best American law firms, an important case because it is a market with substantial competition over salaries. ${ }^{150}$ According to Professor Roth, competition in this market has not been confined to wages. The market has also experienced serious unraveling, in many ways parallel to that experienced in the judicial clerkship market, but with important differences as well. In particular, much of the unraveling has come in the recruitment and hiring of students for summer positions as "summer associates."... [T]he competition to recruit and hire the most promising summer associates has become a proxy for entry-level hiring.

A third example of stage 1 unraveling that led to inefficient matching was the process for the allocation of college football teams to bowls prior to adoption of the current Bowl Championship Series (B.C.S.) mechanism. ${ }^{152}$ Professor Roth illustrates the unraveling problem by describing the selection of teams by nineteen post-season bowls at the end of the 1990-91 season. To prevent unraveling, the NCAA had designated a particular date as "Pick-em Day," just before the final two games of each team's season. Bowl sponsors violated the restriction, however, some selecting teams almost two weeks before. As a consequence, the teams ranked number one and number two at the end of the season played against different opponents in different bowl games, to Professor Roth an illustration of inefficient matching.

Finally, Professor Roth presents examples of entry-level hiring markets not characterized by serious unraveling: entry-level MBA graduates and business school marketing professors. ${ }^{153}$ Professor Roth, however, cannot explain why unraveling in these markets is "regarded as being of manageable proportions."

\section{Stage 2 Markets}

Stage 2 markets are those in which uniform hiring dates are set, but where the market is plagued by congestion and mismatches at the time of ultimate transaction. One example is the market for Japanese university graduates where a series of agreements are entered by firms through various employer's federations, university associations, and government ministries that attempt to set fixed recruiting and offer dates. ${ }^{155}$ According to Professor Roth, these agreements have been unsuccessful because of early recruiting. ${ }^{156} \mathrm{~A}$ second

150 Id. at 1004-07.

$151 \quad$ Id. at 1004-05.

152 See id. at 1007-13 for the Roth and Xing discussion of bowl games. Their paper was published before the institution of the current B.C.S., see infra text accompanying notes 299-301, though that mechanism is clearly in the spirit of Professor Roth's analysis.

153 Roth \& Xing, supra note 11, at 1013-14.

$154 \quad I d$.

155 Id. at 1014-16.

$156 \quad I d$. 
example is the market for clinical psychology interns, where time limitations have been introduced, also unsuccessfully. ${ }^{157}$

\section{Stage 3 Markets}

Stage 3 markets are those in which a centralized market-clearing mechanism has been adopted. Here are Professor Roth's best examples, chiefly entry-level medical positions, in which different medical specialty associations, both in the United States and in England, have adopted the medical match (such as the National Resident Matching Program (NRMP) through which hospitals and aspiring residents are matched. ${ }^{158}$ Professor Roth has been both a strong advocate of the adoption of medical match-like programs and the designer of many of those programs. ${ }^{159}$ Professor Roth has also studied college fraternities and sororities which have adopted such matching programs to control unraveling, called "rushing," in membership recruiting.

\section{Stage 4 Markets}

Stage 4 markets are those in which some centralized matching mechanism has been adopted, but where unraveling occurs nonetheless. Professor Roth presents several examples of medical markets characterized by this unraveling. One such market comprises hospitals at "the least competitive end" that find that they are unable to fill all their resident positions through the NRMP match. ${ }^{161}$ According to Professor Roth, "[i]t appears that some of the hospitals that regularly fail to fill all their positions have begun to recruit foreign medical graduates before the match." 162

Conversely, among the most competitive hospitals, several specialties "have begun to suggest to applicants that they must take part in audition electives if they wish to be seriously considered as candidates for residencies." 163 An "audition elective" requires on-site work in the hospital's clinic for a period of several weeks, and is a way for the hospital to learn the abilities of the candidate and the candidate to learn about the hospital. ${ }^{164}$ According to Professor Roth, in a 1991 survey, $80 \%$ of students interested in orthopedic surgery or neuro-surgery reported that they had been told by a

$\begin{array}{ll}157 & I d . \text { at } 1016-18 . \\ 158 & I d . \text { at } 1018-22 . \\ 159 & I d . \\ 160 & I d . \text { at } 1019-20 . \\ 161 & I d . \text { at } 1023 . \\ 162 & I d . \\ 163 & I d . \\ 164 & I d .\end{array}$


program that they were more likely to be highly ranked in the match if they participated in an audition elective with that program. ${ }^{165}$

Professor Roth has found similar unraveling in the market for articling lawyers in Canada. As a condition for admission to a provincial bar association, a Canadian law school graduate is required to spend ten months "articling"-working as a non-admitted associate-in a Canadian law firm. In 1986, the law association in Ontario adopted a matching program like the medical match for law firms and articling students. ${ }^{166}$ Over time, however, there has been "a tendency toward unraveling" as law students have felt advantaged by working in a law firm during the summers after their first and second years, giving both the firms and the students advance information about each other for the purpose of the rank-order selection in the match. ${ }^{167}$

\section{Other Markets with Unraveling}

Finally, Professor Roth has identified a miscellaneous set of markets that appear to experience timing problems, inferred chiefly from the observation of forms of regulation that have been adopted to control hiring transactions. One is the market for entry-level professional athletes in which various sports leagues have adopted organized drafts, allocating sequential choices to teams in inverse order of the team's success in the previous season. ${ }^{168}$

A second set of markets of this nature is medieval and modern commodity markets. Many medieval markets were controlled by statutes or town bylaws that prohibited "forestalling": selling goods before they reached the open and organized market. ${ }^{169}$ Professor Roth presents other medieval examples in which sales outside of the primary markets were disallowed. ${ }^{170}$

Finally, Professor Roth gives the example of the facts in the famous U.S. antitrust case, Chicago Board of Trade. ${ }^{171}$ There, the Board of Trade had designated a particular period of time-named the "call" period-during which members would trade for the purchase and sale of grain in transit to Chicago. ${ }^{172}$ The members of the Board of Trade adopted a rule preventing members from trading "to arrive" grain during the time from the end of the call period to the beginning of the next business day's general trading session at any price other

$165 I d$.

166 Id. at 1024.

167 Id. at 1024-25.

168 Id. at 1025-26.

169 Id. at 1027 (citing LouIs F. SALZMAN, ENGLiSH TRADE IN THE MidDLE Ages 75-76 (1931)).

170 Id. at 1028 n.68 (citing SALZMAN, supra note 169 , at 132-33).

171 Bd. of Trade v. United States, 246 U.S. 231 (1918).

172 Id. at 236. 
than the closing price at the end of the call period. ${ }^{173}$ The U.S. Supreme Court ruled that the restriction was a reasonable means of creating a market. ${ }^{174}$ To Professor Roth, the practice is another example of a market in which it became necessary to regulate transaction timing. ${ }^{175}$

Professor Roth's work has been notable in identifying a feature of market operation-the timing of market transactions-largely neglected in the economic study of markets. His work has been widely influential. This paper will analyze in more detail each of Professor Roth's examples of unraveling. ${ }^{176}$ Next, however, this paper presents a somewhat different economic analysis of the problem.

\section{A Different Approach Toward the Timing of Market Transactions}

This Part presents a different analysis of markets with timing peculiarities. Section A presents the economic analysis and applies it to the market for judicial clerks. Section B reevaluates the results of the Harvard-Chicago Study. Section $\mathrm{C}$ discusses the curious experience of Yale Law School, which has viewed itself as particularly disabled in the clerkship market because of its ungraded first semester, unique among law schools. Finally, Section D addresses the other markets that Professor Roth has identified that are said to possess timing problems.

\section{A. Markets with Timing Peculiarities from the Vantage of Market Search}

Professor Roth and those writing in what I will call the Roth tradition (including the authors of the Harvard-Chicago Study) begin their analysis with a focus on a particular market for which an optimal moment for market transactions can be specified. Entry-level labor markets in law, medicine, sports, or other industries fit this description because workers enter these markets following the completion of some level of schooling or preparation. Similarly, since college bowl games are played only at the end of a football season, the bowl game market can be said to begin at the end of the season. Having specified an optimal time for a market to begin, the Roth tradition then addresses the subject: why are market transactions occurring at times other than at that optimal moment?

From a different standpoint, however, the subject of the timing of market transactions is a peculiar one. Consider the subject of timing from the vantage of the participants in the market and of the determinants of market search in

$173 J d$. at 237.

174 Id. at $239-41$.

175 Roth \& Xing, supra note 11 , at 1028.

176 See infra Section II.D. 
contexts of imperfect information. Since the work of George Stigler, it has been well accepted that a market participant can be expected to continue to search for a product as long as the net expected returns from further investments in search are positive. ${ }^{177}$ Market transactions occur-a consumer buys a product at a particular time-when the marginal benefit net of costs from further search becomes zero or, put slightly differently, when the marginal costs of obtaining further information about the product exceed the marginal expected gains from acquisition of that information.

Most (though not all) of the markets described and analyzed by Professor Roth are two-sided markets in which both buyers (say, employers) and sellers (workers) are engaged in the search process. ${ }^{178}$ This fact slightly complicates, but does not change, the basic analysis of search. It simply means that search by both parties will continue until both parties have concluded that the net benefits from further search are exhausted. The parties, of course, will need to mutually agree in order to enter the transaction. One party may be ready to transact, having concluded that expected benefits from further search have been exhausted, while the other party may choose to engage in further search. Again, this is a complication, but does not change the analysis. The market transaction will occur at the time when both parties have concluded that the costs of further search exceed expected benefits.

Another potential distinction between the markets that Professor Roth examines and more typical commodity markets is the level of uncertainty attending the transaction. The entry-level employment markets that form the focus of Professor Roth's work are attended by potentially high levels of uncertainty on both sides. Employers, for example, may be very uncertain as to the future productivity of potential workers; workers may be uncertain as to the quality of the job they will be able to obtain at later times in the market. ${ }^{179}$ But this difference is surely no more than a matter of degree. All markets are attended by some level of uncertainty concerning price or quality of the product. Unless hopelessly compulsive, none of us can ever be certain that we have canvassed every potential product that might meet some current need, or that there is not some seller somewhere from whom we might buy the product at a better price. Again, at some point, a buyer even of a simple commodity must make a judgment as to whether further market search is worth the trouble;

177 George J. Stigler, The Economics of Information, 69 J. POL. ECON. 213 (1961), reprinted in THE ORGANIZATION OF INDUSTRY 171 (1968).

178 The medieval and modern commodity markets he discusses are simple one-sided markets.

179 This feature of these markets is emphasized in Li \& Rosen, supra note 11 . According to the $\mathrm{Li}-\mathrm{Rosen}$ analysis, unrayeling in labor markets is a market failure resulting from the absence of Arrow-Debreu securities markets for human capital. The unraveling, thus, is motivated by risk aversion; early contracting serves as a form of insurance against adverse placement at later times in the market. 
this is the economic calculation. Differences in transaction time across buyers reflect differences in search costs or in their evaluation of these uncertainties. That one individual is a decisive shopper who buys a product after limited search, while another visits multiple stores and the Internet, means only that the economic determinants of market search are different for the two.

Viewed this way, the question of the appropriate timing of market transactions becomes a straightforward matter. The timing of transactions in any market is a function of the relationship between the costs and benefits of further search to market participants. Transactions take place when the costs of further search exceed expected benefits and, therefore, are a function of the determinants of those costs. This is not to make the subject uninteresting. As Stigler has shown, there will be greater expected benefits from continued search as there is greater price or quality dispersion in the market. ${ }^{180}$ And, of course, the determinants of search costs, such as the value of time, the costs of obtaining information, the level of risk aversion deriving from expected uncertainty, and the like, remain of economic importance and interest. The ultimate resolution of the timing question, however, will still be determined by the intersection of the curve defining the value of further information and the curve defining search costs.

As mentioned, in Professor Roth's work, the timing of transactions appears as a more prominent issue because the markets he has studied can be defined as "beginning" at particular moments. Thus, entry-level employment markets can be defined as "beginning" only after the moment of graduation from a high school, college, or professional school. Other of the markets that Professor Roth analyzes possess similar potential defining points. One can define the market for college football bowl games as beginning after the end of the football season or on the date that the NCAA designates as "Pick-em Day." Medieval markets were often defined to occur on specific days in specific locations. The Chicago Board of Trade, like other commodity and stock markets, designates fixed hours of operation. As I shall discuss, many of the markets Professor Roth has studied have been subjected to some form of regulation of transaction timing. In these markets, the regulation defines-or, at least, attempts to define-the time the market begins.

It is the existence of a specific day or moment that can be identified as the point at which the market begins that gives the concept of unraveling its coherence. In the Roth tradition, unraveling consists of market transactions that occur at times earlier than the optimal market beginning time. It is quite another matter, however, to attach normative significance to the unraveling concept. The Roth tradition uniformly regards unraveling as a problem, a disturbance, an obstacle to the achievement of efficient market transactions. As 
a consequence, the normative approach of the tradition is to subject markets characterized by early transactions to some form of timing regulation such as by the adoption of a centralized matching program; if the market is regulated, but early transactions still occur, the Roth tradition proposes more extensive regulation. Given the existence of regulation, the normative condemnation of unraveling may be defensible. Instances of unraveling mean that the timing regulation is being violated. But the question is more complicated for markets without regulation as well as for regulated markets where the question is whether the regulation can be defended.

As a general matter, the concept of an optimal beginning date of a market is an artifact and is inconsistent with the economic model of market search. This is apparent from many of the markets that Professor Roth studies, though the point is a broader one. For example, in his description of the market for college football bowl games, Professor Roth defines unraveling as the entering of market transactions prior to the NCAA's Pick-em date. ${ }^{181}$ But the Pick-em date was simply a date chosen by some process by the NCAA; it preceded the end of the football season by several games. If the end of the season is the optimal moment for the market, the Pick-em date itself constitutes unraveling. Similarly, for the market for judicial clerks, unraveling is defined as the extension and acceptance of offers prior to the beginning of a student's third year of law school. But why is it optimal to transact for clerkships at the beginning rather than at the end of the student's third year when all the student's law school grades will have been recorded?

When considering markets from the standpoint of market search in the context of costly information, it is not evident that there is a single beginning time for market transactions that is optimal in any sense. Market transactions occur when the parties believe that they possess sufficient information-relative to the costs of obtaining further information - to enter the deal. Imagine, for example, the market for high school graduates who have decided not to proceed to college. This market is not inconsiderable. In 1999, 2,897,000 persons graduated from U.S. high schools. ${ }^{182}$ Of this number, $62.9 \%-1,822,213-$ proceeded to college; ${ }^{183}$ the remainder, $1,074,787$, entered the entry-level job market. It is possible, as with other levels of education, to characterize the market for high school graduates as beginning on the date of high school graduation. But what do we make of unraveling from that beginning time? Consider a high school student, confident that college is not for him or her (because expected net benefits are negative), and who knows that he or she will need a job after graduation. The student may surely engage in job search, may

181 See Roth \& Xing, supra note 11, at 1007-13.

182 U.S. Census BurEaU, STATISTICAL ABSTRACT OF thE UNITED STATES: 2001, at 164 tbl.

262.

183 Id. 
try out jobs-during summers or after school part-time or full-time-that might be attractive as a career and, if fortunate, might succeed in securing an attractive job prior to graduation by demonstrating his or her abilities to an employer. By the definitions with which we have been working, this is evidence of unraveling in the high school job market, but is it a sign of a problem in the market?

The analytical point does not depend on the high school example. Imagine a college student certain that the costs of graduate or professional education are greater than expected benefits. When this student pursues future job interests by leaming about industries or alternative potential careers or, perhaps again, secures a job offer or expectation based on summer work, is it useful to view the college job market as unraveling? The point extends to professional job markets analyzed by Professor Roth. At several law schools at which I have taught, securing a part-time job with a law firm, thus increasing the prospects of future employment (or securing a volunteer job as a clerk for a judge), was possible for only the very best and most able students, though was an aspiration of the entire student body. At what point is it useful to regard the market for legal careers beginning? The concept of unraveling and the welfare implications of its existence require some further clarification.

In order to see more clearly what is distinctive about some of the markets that Professor Roth has studied and in order to more carefully understand what might be called unraveling, it is helpful to compare job markets without unraveling to markets, like the market for judicial clerks, that operate substantially differently. Professor Roth does not claim that all markets-even entry-level labor markets-are characterized by unraveling. For example, he concedes that there is little unraveling in entry-level markets for MBAs, ${ }^{184}$ and nor has he discovered unraveling in a wide range of other entry-level labor markets. ${ }^{185}$ Many of these markets are considerable and are surely complex. In 2000 , for example, 112,258 graduate students received MBAs and entered the job market, ${ }^{186}$ securing jobs, surely, at many thousands of different employers. What distinguishes markets of this nature from the market for judicial clerks?

In most labor markets, there are many dimensions that define the relative attractiveness of different jobs, which is to say, there are many dimensions over which employers compete for employees. In different jobs, salaries will differ; future wage tracks will differ; working conditions will differ; the extent to

184 Roth \& Xing, supra note 11, at 1013-14.

185 Id. As broadly as he defines unraveling - to include the pre-commitment acquisition of information - I would expect that he is probably wrong in this respect, and that these labor markets would indicate "unraveling" according to his definition, at the minimum in the form of the acquisition of substantial information prior to graduation through summer jobs that resemble audition electives in surgery.

186 U.S. Census Bureau, StatistiCal Abstract OF THE UnITED States: 2002, at 177 tbl.280 [hereinafter STATISTICAL ABSTACT 2002]. 
which the job can be expected to contribute to development of the worker's human capital will differ through the nature of the job or through differential assignments; stability of future employment will differ; and of course, there are geographic differences. In all of these dimensions, candidates will sort themselves into jobs throughout the market as they differentially evaluate these factors given the job offers that they receive. Over time, employers will adjust various dimensions of the jobs they offer-by changing starting salaries or changing working conditions-in response to demand and supply changes in the labor market. These continuous adjustments in the price and quality of employment allow these labor markets to clear.

The market for judicial clerks is substantially different. The clerkship market is distinctively more truncated in most of these dimensions of job choice. Although individual judges will have different temperaments and will work their clerks more or less intensively, job conditions themselves are fungible over a large range. The content of the workload may differ somewhat across circuits, though in ways uncontrollable among judges of the same circuit. In many other respects, however, there are no differences across appellate clerkships. Salaries are fixed, set by Congress. ${ }^{187}$ Geographic differences are of minimal importance because of the heavy and demanding work load of the clerkship, though applicants may prefer particular locations on account of family or relationship commitments. Differences in job stability are infinitesimal; as Judge Wald informed us, clerks are almost never fired. ${ }^{188}$ Importantly, the job extends for only a year; two years, at most. Thus, even where there are differences across clerkships, their expected value is low because of the short tenure of the job.

Given the absence of difference across these dimensions, one principal apparent difference among clerkships is in what might be loosely called the "prestige" or the value of the clerkship which derives from the general reputation of the judge. As has been mentioned, some judges stand out as "feeders" to the Supreme Court, though the realistic probability of a Supreme Court clerkship is low for any appellate clerk. Judge Kozinski reported (and my experience confirms) that clerkships on the D.C. Circuit are differentially attractive to applicants. ${ }^{189}$ Similarly, clerkships with well-known judges in other circuits are regarded as relatively more prestigious and, thus, subject to greater competition among applicants. The greater prestige may derive from the greater level of competition for these clerkships, indicating that an able judge has evaluated the applicant as superior to a large set of able competitors. It may

187 Salaries for judicial clerks differ slightly based upon experience and bar admission, but still are non-negotiable. I am grateful to Judge Richard A. Posner for this observation. The HarvardChicago Study notes the lack of flexibility in clerk salaries. Harvard-Chicago Study, supra note 7, at 799 n. 14.

188 Wald, supra note 6, at 153.

189 See supra text accompanying note 41. 
also relate to future productivity if working for a year for a relatively more able judge makes the clerk a better lawyer. The prestige of the clerkship, thus, may well affect the future legal career of the clerk.

There is no negotiation, however, over prestige. The prestige of any clerkship, deriving from the reputation and ability of the judge, is fixed at the time of application. In contrast, in other professional job markets, the extent of negotiation prior to the employment agreement may well differ. In many jobs, salaries are fixed in the sense that they are announced in advance and are not subject to negotiation, though in other contexts, negotiation takes place, especially for the most attractive candidates. Negotiation may more generally take place over potential future assignments, moving expenses, or other less central perquisites. Moreover, a form of negotiation occurs over time as employers adjust starting salaries, job definitions, and working conditions in response to supply and demand forces in the market. These adjustments, as well as any express negotiation, allow intensity of preference to be expressed by the employer for a candidate or set of candidates and by the candidate for the job.

In contrast, in the market for judicial clerks, there is and can be no negotiation, nor is there adjustment over time in job description or working conditions. Again, salaries are fixed; the location is fixed; the workload is exogenous and cannot be influenced; the judge's temperament is largely fixed; the prestige of any single clerkship is a constant. None of these mechanisms are available for adjustment in order for either the judge or the applicant to register intensity of preference. In the market for judicial clerkships, an offer from a judge is a take-it-or-leave-it offer.

There is, however, one dimension that remains subject to adjustment to market forces-even negotiation-in the market for judicial clerks: the time at which the clerkship offer is extended. Though a judge cannot offer a higher salary, cannot change the job description, nor alter general working conditions in any dimension, the judge can control the timing of the clerkship ofter. The timing of the offer, thus, becomes a term of trade in the clerkship market transaction. A student registers intensity of preference, first, by applying to the most favored judge or judges with whom the student's application might be successful. A judge can register intensity of preference for a candidate, in turn, by offering the candidate a clerkship position early in the process. Since there is substantial uncertainty attending any clerkship application, no matter how able and self-confident the candidate, an early offer may have substantial value.

By this analysis, the timing of the offer becomes a principal, perhaps the principal, currency in clearing the market for judicial clerks. In many respects, the clerkship market resembles an auction. Research into the quality of the object of the auction takes place largely prior to the beginning of the market. All offers are take-it-or-leave-it offers. In auctions, however, bidders who value an object more highly than others can prevail by offering a higher price. Money 
is not an available currency in the market for judicial clerkships, nor are there other available currencies. In their place, the timing of the offer becomes the currency.

In a market in which the dimensions of the terms of trade are so truncated, one should expect the conduct of the market to be different. Because of the takeit-or-leave-it character of the ultimate transaction, as with an auction, both judges and clerkship candidates can be expected to engage in substantial premarket research in anticipation of the market transaction itself. Thus, it is not surprising that there are strategic efforts by the parties to obtain the most desirable matching.

Indeed, the apparent rampant maneuvering by both judges and applicants-in arranging, as best as possible, a particular sequence of interviews; in trying to avoid calls from a less-favored judge prior to hearing from a more-favored; in the often delicate request for additional time for decision or the demand for an immediate response-can be explained by a further explication of the auction analogy. A market in which multiple judges are competing for clerks resembles, not a single auction, but a collection of competing auctions conducted nearly simultaneously. A clerkship applicant faces a situation in which he or she must decide, first, to which of the 238 appellate judges applications will be sent, ${ }^{190}$ knowing that, however unique he or she may be to family and friends, there will be many other applicants in the pool with comparable college and law school records. Second, the applicant must also expect that some and perhaps all of the judges to whom applications are sent will engage in the early-offer process. The applicant knows that, if a clerkship offer is extended and not accepted within a relatively short period, the judge will move on quickly to other comparable candidates in order not to lose them to the competition of other judges. This means that, as in an auction, the applicant must be ready to accept or reject within a limited period of time the offer of any of the judges to which he or she has applied. But again, the applicant may be participating, not in a single auction, but in a collection of auctions operating at the same time. In a market of this nature, one must surely expect strategic interviewing. Indeed, the substantial efforts of judges and students to align themselves with the most likely partners to a deal-the maneuvering-represents a rational and beneficial means to ensure success of the mutual search. ${ }^{191}$

This process may appear different than search in more traditional markets, but the differences are superficial. Again, a judge can be expected to make an offer at the point when the judge concludes that the marginal value of further

190 Harvard-Chicago Study, supra note 7, at 886 . Many students will simultaneously apply to district court judges as back-ups, but this point does not change the basic analysis.

191 Of course, these various features of the clerkship market are likely to obtain at whatever time the market begins. I discuss this point in more detail infra Section II.D. 
information about the clerk is worth less than its costs. In this market, however - though it is true in all labor markets and in many other markets as well $^{192}$ - the costs of further search include foregoing the opportunity of securing the clerk because of intervening rival offers. Although much of the literature on the clerkship market has emphasized that judges are extending offers on the basis of scant information about the student's abilities, the claim is not generally accurate and neglects the economic dimension of the subject. Even at the beginning of a student's second year of law school, the student will have established a substantial record to serve as a basis for evaluation. The student will have been admitted to a college of some reputation, created a college record, engaged in employment over college summers, taken the LSATs, been admitted to a law school of some reputation, have received some number of law school grades, and had one summer of usually law-related work. The student will also have been interviewed by the judge and the judge's clerks and may have been able to provide recommendations from college or law school faculty. There is no coherent economic sense in which an outside party can claim that this information is insufficient. If the information is sufficient enough that a judge would extend a clerkship offer, it is economically sufficient.

The complaint that this information is an inadequate grounds for hiring, at base, is an empirical assertion that there is a net marginal benefit from the acquisition of further information about the candidate. As I shall discuss in further detail below, for some judges this may be true. ${ }^{193}$ For other judges, however, especially taking into account the costs of competition at later times, the marginal value of another semester's or another year's law school grades for the evaluation of the candidate may well be less than the costs incurred by delaying the offer. Just as we imagine the existence of decisive shoppers in other markets, there is a return from becoming a decisive shopper in the market for judicial clerks.

Judge Kozinski argued that there existed a natural time at which there was sufficient information about an applicant to extend an offer. "around February or March of a student's second year of law school."194 The authors of the HarvardChicago Study, similarly, believed that they had proved that the clerkship market was inefficiont because the timing of the market differed as between 1998-99 and 1999-2000. ${ }^{195}$ Again, imagining a single ideal time or a time that

192 The purchase of real estate or the submission of articles to law reviews or academic journals are other examples.

193 Professor Roth explains the lack of unraveling in the market for assistant professors in similar terms: "unraveling may be impeded if the uncertainty associated with hiring early is relatively large compared to the possible benefits." Roth \& Xing, supra note 11, at 1036-37.

194 Kozinski, supra note 6, at 1710.

195 As the authors of the Harvard-Chicago Study put it:

For skeptics who tend toward the view that the current market... must be operating efficiently, the data presented here raise serious questions. If 1999-2000 was efficient, then was 1998-1999, when hiring occurred substantially later, also efficient, or was it inefficient? 
would remain constant across years is innocent of the economic dimensions of the market. There is a positive return to a judge from enhancing his or her ability to predict the quality of clerks from restricted information. Lower levels of information about an applicant, of course, imply greater uncertainty attending the selection. But judges can be expected to invest in techniques of prediction in order to gain the return from securing a more able clerk with the currency of an early offer. The moment at which an offer will be extended will depend in any case upon the judge's confidence in his or her predictive ability relative to expectations of the quality of clerk that will be available after further search. The gains from investments to secure and process information about future prospects is a well-known economic phenomenon. ${ }^{196}$

This understanding of the distinctive character of the market for judicial clerks allows a more careful definition to be given to the concept of market unraveling. The Roth tradition employs the term "unraveling" to describe any form of market-related activity that occurs prior to the defined beginning date of a market. Thus, examples of unraveling include early clerkship or college bowl offers, the NBA or NFL draft, summer jobs with law firms in America or for articling students in Canada, "audition electives" in various surgery specialties, sales of products outside the market-forestalling-in the Middle Ages. This broad definition of unraveling is not generally useful.. By this paper's analysis, however, it is possible to distinguish activities that represent forms of market search--investments by parties in the market to gain further information prior to engaging in market transactions-from market transactions themselves in which time of the transaction serves as a currency to clear the market. Thus, this analysis would distinguish summer jobs in law firms or audition electives required of prospective surgeons from the acceleration of offers to clerks or medical residents because of restrictions on the use of alternative terms of trade to clear the market.

This is a substantially different approach from that of the Roth tradition and implies a substantially different normative evaluation of the various examples of market unraveling. By this analysis, those forms of unraveling that consist of investments to obtain further market information become entirely unproblematic. Summer jobs in law firms or audition electives for aspiring surgeons are mechanisms through which participants in the market gain greater

More generally, given how much the timing in this market has bounced around over the years, it seems hard to assert that any current resting point is efficient.

Harvard-Chicago Study, supra note 7, at 833 .

196 See Anthony T. Kronman, Mistake, Disclosure, Information, and the Law of Contracts, 7 J. LEGAL STUD. 1, 13-14 (1978). 
information - the employer about the candidate; the candidate about the job. ${ }^{197}$ They are comparable to any other form of market search prior to purchase.

The analysis is somewhat different of those examples in which unraveling represents the use of time as a currency for transaction. The interesting question becomes: why has the timing of the transaction become a currency? As we shall see in a review of the various markets studied by Professor Roth, ${ }^{198}$ time becomes a currency in contexts in which there generally appear to be external restrictions on the use of price to clear the market. Where the use of price as a market-clearing mechanism is constrained in some way-as it is in the market for clerks since Congress sets a fixed salary-transaction timing emerges as a currency in order to clear the market. Thus, far from an instance of market failure, time becomes the medium through which market forces express themselves.

Professor Roth's analysis of market unraveling concluded that it led to inefficient market outcomes because of ex post mismatches among parties in the market. As we shall see, there are several ways in which this analysis is incomplete. First, each of the models in this tradition defines efficiency by comparing ordinal matches-first-choice with first-choice; second with second; and the like. It is this definition, of course, that provides support for the adoption of centralized matching mechanisms, like the medical resident match, which operate on the basis of ordinal rankings. Ordinal rankings and ordinal matches, however, necessarily ignore all but uniform differences in intensity of preference of market choices. Free-flowing markets recognize different magnitudes of differences in intensity of preference through their various adjustable terms of trade such as price. In markets in which many of these terms are restricted, the timing of the transaction becomes the currency to register intensity of preference. Where differences in intensity of preference are acknowledged, it is no longer possible to conclude that unraveling of any form generates global market inefficiencies.

Second, none of Professor Roth's models, nor any of those in the Roth tradition, include the costs and benefits of information acquisition as elements. As a consequence, the conclusion of inefficiency follows by definition from differences in matching as between periods with lesser versus greater information. That is, according to the Roth model, there exists a set of candidates at time $T-l$ attended by great uncertainty about individual productivity; at time $T$, the same set of candidates are present, but with less uncertainty about productivity. Given these assumptions, it is straightforward

197 The Harvard-Chicago Study adverts to the information gain to law firms and students from summer associates, Harvard-Chicago Study, supra note 7, at 858 , but continues to describe it as a form of unraveling.

198 See infra Section II.D. 
that there will be efficiency losses from matches entered at time $T-l$ versus at time $T$.

The Roth model resembles the analysis of commons problems in the property rights literature. There has been substantial study and identification of socially inefficient expenditures on search where property rights to a resource can be captured by first possession. ${ }^{199}$ Thus, in many resource contexts-a gold rush, for example, or fish for which the state has defined a limited seasonindividuals will invest socially excessive amounts in search because of the distributional gain that attends being the first to capture the resource. ${ }^{200}$

In each of the resource contexts, however, as in Roth's model, the conclusion that search investments are inefficient derives from the assumption that the value of the resource to be captured remains constant over time. Thus, halibut are halibut, gold is gold; in these models, the resource has a fixed value to society regardless of when that value is realized. As a result, expenditures to capture the resource earlier than rivals are socially wasteful since they achieve only a distributive and not a productive gain.

In employment contexts, such as the market for judicial clerks or medical residents, in contrast, the value of the resource to the judge changes over time. Clerks are not fish, and it makes a difference to a judge to capture a more able and congenial clerk. A more discriminate model would introduce the costs and benefits both of the search process and those costs associated with the effect of the passage of time on the expected value of those applicants remaining in the market. Thus, at a particular time, a judge estimates an expected value of an applicant, knowing that that estimate is attended by error, which is to say, uncertainty over the clerk's productivity. The judge can invest in obtaining further information about the applicant to reduce that uncertainty. But those investments will be attended by costs in two forms: the cost of the investigation itself plus the cost that derives from the declining value of available clerks as time progresses and other judges select the more able among the clerkship pool. Of course, clerks are not fish in a second way. The market is complicated by the fact that the applicants are engaging in exactly the same consideration: determining whether to invest in an interview with a more

199 Yoram Barzel, Optimal Timing of Innovations, 50 REV. ECON. \& STAT. 348 (1968); David D. Haddock, First Possession Versus Optimal Timing: Limiting the Dissipation of Economic Value, 64 WASH. U. L.Q. 775 (1986). 1 am grateful to David Haddock and Fred McChesney for alerting me to this literature.

200 For an excellent description of many resource contexts of this nature, see Louis De Alessi, Gains from Private Property: The Empirical Evidence, in PROPERTY RIGHTS: COOPERATION, CONFLICT AND LAW 90 (Anderson \& McChesney eds., 2003). As an example of the problem, De Alessi shows that to prevent overfishing, Alaska was compelled to progressively reduce the open season for halibut from nine months to two days as fishers invested in faster and more efficient boats and equipment. Id. at 100-01. 
favored judge, knowing that the pool of available judges is declining over time.

Finally, it might be thought that Professor Roth's conclusion that there are "potentially large losses in efficiency" to the optimal moment ${ }^{203}$ can be supported by considering unraveling in the market for clerks or other entry level employees as a coordination problem resembling, say, the prisoners' dilemma. Isn't it proof of inefficiency that matches entered at time $T$ would be different than matches at time $T-1$, where there is greater aggregate information available at time $T$ ? Wouldn't coordination that shifted the matches to time $T$, as coordination in the prisoners' dilemma, eliminate that inefficiency?

The market for clerkships is not a prisoners' dilemma. In the prisoners' dilemma, payoff assumptions are introduced that provide that the two prisoners will be mutually better off if they coordinate their actions than if either maximizes its respective interests individually. Of course, besides the context of the prisoners, there are many other examples in which the payoff conditions are such that all parties will be better off if they coordinate, rather than if each maximizes individual interests.

Those payoff conditions, however, do not hold for the market for judicial clerks or, as shall be shown later, for the other assortative matching markets studied by Professor Roth. In the prisoners' dilemma, each of the two persons arrested faces the risk that, if the other person maximizes his or her individual interest by confessing, the one who refuses to confess will be worse off. Coordination between them-the agreement of both to refuse to confesseliminates that risk to the benefit of both. ${ }^{204}$ The market for clerks is substantially different. The judge who extends an early clerkship offer is maximizing individual interest, as is the applicant who accepts the offer. It is possible that, as in the prisoners' dilemma, judges who fail to enter the early offer process are worse off as a consequence. But coordination among the judges and applicants does not benefit all. If the judge and the applicant who fear being less-favored are accurate in their estimations, coordination to postpone the market harms them; the clerks or the clerkships that they obtain from the delayed process will be less-favored than those that can be secured through participation in the early-offer market. ${ }^{205}$

201 There are two principal differences between the clerkship market and Judge Goodwin's calf scramble, see supra notc 68 . It makes a difference to a judge which clerk is selected; in the calf scramble, one grabs the closest calf. Second, the calves resist; the clerks are searching.

202 Roth \& Xing, supra note 11, at 992.

203 See supra text accompanying note 129

204 Of course, the coordination of the prisoners does not benefit the state and, thus, resembles cartelization of a market by which sellers benefit from coordination, though society loses.

205 The authors of the Harvard-Chicago Study acknowledged that some judges or applicants might be better off by engaging in the early-offer process, but minimized the significance 
Indeed, it is the benefit from discovering an able clerk that creates incentives for judges to invest in techniques of prediction. In this respect, the market for judicial clerks is no different from many other markets in which specialized knowledge allows a buyer to acquire a valuable object in advance of the revelation of its value to the wider set of market participants. ${ }^{206}$ Markets for mineral rights, for art, for antiques, and for stocks, are all markets in which buyers-like judges-make predictions of future value, attended by uncertainty, and gain a return according to the accuracy of their predictions. A judge who discovers a worthy clerk and extends an early offer is no different from a buyer who discovers an undervalued antique or a prospector who buys land rich with undisclosed minerals. Those buyers later in the market denied the antique or the land or the clerk may claim that a "cost" has been imposed upon them, but it is not a cost that in a competitive economy commands normative significance. ${ }^{207}$

Another way of observing this point is to describe the early-offer process as creating a form of wealth effect. As explained earlier, although appellate clerkships are fungible over a large range, the principal difference among them is in the dimension called "prestige:" some clerkships, because of the relative prominence of the judge, are more attractive to applicants than others. ${ }^{208}$ As a consequence, other things equal, prominent judges are able to secure the most qualified clerks. The early-offer process, however, changes the distribution of judicial wealth by adding an additional currency to the market, allowing a relatively less prominent judge - if he or she is willing to invest in making an early prediction-to compete for those relatively more qualified clerks desirous of reducing risk by accepting an early offer. This is only a more general description of Judge Kozinski's point describing himself as an upstart who

of the point on the grounds that the "Pareto [efficiency] standard is notoriously limited in its usefulness, for rarely can one make some people better off without making even a single person worse off." Harvard-Chicago Study, supra note 7, at 800 . They turned the remainder of their analysis to "two other, more useful conceptions of efficiency": 1) "[m]aximizing the 'sum total of satisfaction' of judges and clerks" in which they concluded that the early offer process is certain to create mismatches and that "insurance" against the risk of a worse match was not clearly desirable, $i d$. at $800-04$; and, 2) "[m]aximizing the production of justice" in which they were unable to resolve whether matching the most able clerks with the most able judges or the reverse, maximized judicial output. Id. at 804; see supra note 73.

206 See generally Kronman, supra note 196.

207 This point is similar to the concept of antitrust injury under the antitrust laws in which harms imposed by the process of competition are held not to justify an antitrust claim. See, e.g, Brunswick Corp. v. Pueblo Bowl-O-Mat, Inc., 429 U.S. 477 (1977).

208 There are many other markets in which some measure of "prestige" of the object of trade affects ultimate terms. In labor markets, the prestige of the position may lead highly qualified individuals to accept a job despite large salary reductions-say, appointment to a position in the White House Counsel's office or appointment to a federal bench (though I do not mean to diminish the public service character of such an appointment). Unlike appointment to a federal bench, appointment to the White House Counsel's office or to a clerkship may well maximize lifetime income. 
needed to extend early offers in order to secure the most able clerks. ${ }^{209}$ The wealth effect provided by allowing time-of-offer to serve as a currency enables judges to compete, though their clerkships may lack the attraction of a D.C. Circuit clerkship or of a clerkship with a well-known or prominent judge. Bankrolled by the currency of an early offer, a less prominent judge can register intensity of preference for a relatively attractive candidate and, perhaps, secure a clerk who would not be available if the competition were constrained to the prestige dimension. Of course, the time-of-offer currency is available to all of the judiciary, and there is no reason to believe that it will only be spent by judges with less attractive clerkships. Even prominent judges can register intensity of preference with the time-of-offer currency. But they need to wade into the early-offer process in order to do so.

The next Section applies this analysis to the findings of the HarvardChicago Study. Later, Section D reviews the broad range of other markets studied by Professor Roth.

\section{B. The Harvard-Chicago Critique of the Judicial Clerk Market Reanalyzed}

This Section reexamines the findings of the Harvard-Chicago Study in light of the analysis presented above of the operation of the clerkship market in the context of market search. According to this view, the market for clerkslike other entry-level labor markets-is attended by substantial uncertainty by both judges and students as to mutual productivity and compatibility as well as to whether, at later times, the pool of available clerks and the pool of available clerkships will be the same. In a market of this nature, we should expect both sides to potential transactions to invest substantially in search prior to actual interaction in order to best take advantage of the time currency. Thus, students will invest to learn about the characteristics of different clerkships, and judges will invest to learn about students so that, when the market unfolds, both parties can take best advantage of the early-offer currency. Using that currency most effectively requires coordination-students identifying judges most likely to extend them an offer; judges finding students that are both most productive and most likely to accept their offers. Pre-market sorting of this nature can be expected in the application process by the student, the response to applications by the judge, in their mutual scheduling of interviews, and in their responses following the interviews to obtain the most successful matches. Once the market commences, again because time is a principal currency, it will operate something like an auction where the first bidder potentially becomes the highest bidder.

209 Kozinski, supra note 6 , at 1719 . He has since become, if he was not then, a major Supreme Court "feeder." 
Where the parties have sorted themselves appropriately based upon their pre-market research - though also because of the pressures of time-judges are likely to extend offers early in the process. Because the college and law school records of many applicants will be roughly similar, judges may well be relatively indifferent as among members of the set of applicants interviewed, and so may insist on rapid responses to an offer in order, if the offer is rejected, not to lose the opportunity to hire other qualified applicants. Again, it is in the interest of applicants to coordinate interviews with favored judges as early in the process as possible. Where successful, applicants may accept offers early in the interview process.

A market of this nature, of course, is far from the ideal of most of the judges who have criticized the clerkship market as well as of the authors of the Harvard-Chicago Study. Their ideal market, in contrast, is one in which judges collect wide amounts of information about the range of student candidates and students about the range of clerkships, after which both decide among the set of possible matchings which is the most attractive to them. Thus, the Harvard-Chicago Study states "[a] foundation for an efficient market is the ability of market participants to consider and compare the alternatives available in the marketplace., 210 The clerkship market is inefficient because "[i]n a market with limited numbers of buyers and sellers, parties are not able to gather information about multiple options and then act on that information to seek out their most preferred alternatives." 211 The current market disadvantages students because it "does not appear to be one in which students have the opportunity to consider a range of options before making their decisions." 212 And it disadvantages judges because they must make hiring decisions on the basis of insufficient information. ${ }^{213}$ Thus, each of the features of the market that the Study describes-interviews leading quickly to offers; offers requiring quick responses; offers being generally accepted; and many interviews being canceled - are phenomena that the Study claims demonstrate inefficiency. As mentioned, it also finds many sources of potential unfairness in the market, with judges seeking recommendations from current clerks, former clerks, faculty brokers, and other friends. ${ }^{214}$

The concept of an "ideal" market, however, is alien to positive economics. The rapidity of the clerkship market is a function of the unavailability of the use of more traditional terms of trade-most obviously, price-that would serve to register a judge's intensity of preference to reflect the expected productivity of the clerk to the judge and to otherwise serve to clear

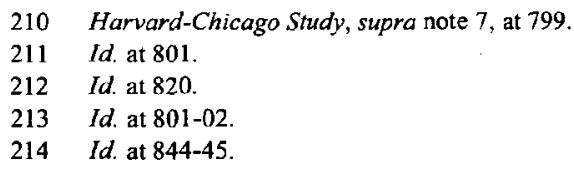


the market. Because of the existence of the time-of-offer currency, judges and students are not able to engage in the leisurely survey of all alternatives to which the Harvard-Chicago Study aspires. ${ }^{215}$ In the clerkship market, the parties must front-load their market search prior to commencement of the interview-offer period of the market. As in any market, the buyers-judgescan be expected to make offers only when they have concluded that they possess sufficient information subject to the costs of further search, and students will only accept offers on the same grounds. The informational basis for such decisions will surely be different than in the more protracted process idealized in the Harvard-Chicago Study, but it cannot in any coherent economic sense be said to be inadequate; otherwise, offers would neither be extended nor accepted.

The Harvard-Chicago Study's findings concerning the character of the clerkship market-interviews lead quickly to offers; offers require quick responses; offers are generally accepted; subsequent interviews are canceledcorrespond exactly to the market search analysis. The principal difference is that the Harvard-Chicago Study finds each of the features of the clerkship market to be failings, rather than the expected working out of market processes given the unavailability of alternative terms of trade. A reevaluation of the Study's findings, therefore, presents a different normative cast to the operation of the clerkship market.

First, the Harvard-Chicago Study interprets its various findings illustrating the rapidity of the market as demonstrating chaos or, at the minimum, the lack of careful deliberation by both judges and applicants over a wide range of potential matching opportunities. This characterization is only available, however, if it is assumed that judges and applicants engage in little pre-market investment in search and are ultimately matched in interviews haphazardly without general attention to ultimate preferences. The Study's findings can be interpreted, conversely, to show the general success of premarket search and sorting. For example, the Study found that, in $34 \%$ of interviews, judges extend offers immediately following the interview; in a cumulative $57 \%$, within two days; in a cumulative $67 \%$, within four days. ${ }^{216}$ Unless large numbers of judges are behaving irrationally, these figures suggest the success of pre-sorting selections at a relatively high level.

Similarly, the Study found that the first offer was received after the student's first interview $36 \%$ of the time; after the second interview, a cumulative $59 \%$; and after the third interview, a cumulative $78 \%$ of the time. ${ }^{217}$

215 Of course, this "ideal" is unrealistic in a deeper sense: in all markets, the extent of the survey of alternatives will be determined by the relationship between the costs and benefits of further search.

$216 I d$ at 814 tbl.1.

217 Id. at $814 \mathrm{tbl} .2$. 
Again, these findings suggest that students and judges are generally highly successful in identifying compatible matches prior to commencement of the interview process.

The Harvard-Chicago Study is highly critical that the offer-acceptance process in the clerkship market occurs prior to the completion of the full set of interviews scheduled by judges and applicants, respectively, on the grounds that neither judges nor applicants appear to be considering the full set of potential matches. Thus, the Study reports, disparagingly, that $64 \%$ of judges began making offers prior to the completion of their scheduled interviews with students. ${ }^{218}$ It is further evidence of market inefficiency that $79 \%$ of judges in 1999 and $66 \%$ in 2000 had subsequently-scheduled interviews canceled by students. ${ }^{219}$ But in the context of a market where continued search is costly, an offer extended prior to an interview or a canceled interview does not indicate inefficiency. Again, where the ideal is the canvassing of all relevant alternatives prior to a judge's selection of a clerk or a clerk-candidate's of a judge, an early offer or a canceled interview may suggest some level of restricted alternatives. Thus, the Study states that this high frequency of student cancellations shows that "applicants are missing the chance to consider what might be more preferred alternatives." ${ }^{220}$ But few shoppers canvass every alternative product. A judge's extension of an offer before completing all scheduled interviews or a student applicant canceling subsequent interviews because of acceptance of an earlier offer is not inefficient, any more than it is inefficient for a consumer to buy a product before reaching the third-choice store on his or her list. To the contrary, it is suggestive of the returns from investment in pre-market search to identify those applicants and those judges with whom the other is most likely to successfully match. Further interviews may be scheduled because of the risk that early-scheduled interviews may not be successful. But where earlyinterviews are successful, it shows not that the process is failing, but that it works.

Finally, the Study's suggestion that it might well be unfair for judges to make use of information sources extraneous to the application-interview process is illustrative of the Study's insensitivity to the benefits of information to the clerkship market and the costs of acquiring it. The Study suggests, for example, that it might be regarded as unfair for judges to acquire information about candidates from other students, from current clerks who knew the candidates in law school, from former clerks, from faculty brokers, or from other of the judge's acquaintances. ${ }^{221}$ With respect to the last of these sources, there is no defense of cronyism. Where a candidate receives a clerkship offer not on the

$218 I d$ at $815-17 \&$ tbl.3.

$219 \quad I d$. at 827 tbl.11.

$220 \quad I d$. at 826.

221 Id. at $840-45$. 
merits, but because the candidate is related in some way to an acquaintance of the judge, surely all will condemn the appointment. But it is a peculiar conclusion for a Study aspiring to enhance the operation of a market viewed as being insufficiently informed to criticize judges for employing available information sources that might enhance their ability to select attractive clerks. Classmates, former classmates, and trusted faculty, all can provide substantial information about an applicant that may not be readily apparent from the written record alone.

The authors of the Harvard-Chicago Study generously have made available the raw data from the 2000 Judge and Student Surveys. Though not reported in the Study's published results, there are various data from the Surveys that suggest that the Study's emphasis on the chaotic and undisciplined character of the clerkship market may be an overstatement. As one example, Table 1, below, presents findings on the number of interviews conducted by judges during the clerkship selection process at the time the judge extended the first clerkship offer. The Harvard-Chicago Study did not report the number of interviews per judge, focusing instead on the rapidity of the extension of offers following interviews. ${ }^{222}$

Table 1: Number of Interviews at First Offer by Early-Offering Judges

\begin{tabular}{lcc}
\hline Number of Interviews & Number of Judges & $\begin{array}{c}\text { Percent of Judges } \\
\text { Responding }\end{array}$ \\
\hline $1-3$ & 5 & 10.6 \\
$4-6$ & 8 & 17.0 \\
$7-9$ & 14 & 29.8 \\
$10-12$ & 5 & 10.6 \\
More than 12 & 15 & 31.9 \\
\hline
\end{tabular}

Source: Derived by author from Harvard-Chicago 2000 Judge Survey (on file with author).

Table 1 shows the number of interviews per judge for that group of judges most likely to be instigating the early-offer phenomenon. In another question, the Survey asked when judges began conducting interviews and making clerkship offers, providing as available answers months between September 1999 (the absolute beginning of a student's second year) to periods following February 2000 (after the reporting of a student's third semester grades). Table 1 segregates off those judges who began conducting interviews during or before December 1999, relatively early in the clerkship market, before the receipt of students' third semester grades. These early-offer judges might be those 
expected to have made decisions based on the least extensive information, illustrative of the irrationality that is purported to be a consequence of the early competition.

The interview figures show a market in which there is far more investment by judges to collect information through comparative interviews than might be imagined from the Harvard-Chicago Study's characterization of the market. Over $42 \%$ of early-offering judges conducted ten or more interviews prior to extending their first offer. Over $72 \%$ conducted seven or more. Almost $90 \%$ of early-offering judges conducted four or more interviews prior to extending a clerkship offer. Even early-offering judges make substantial investments to evaluate candidates.

\section{Table 2: Shortest Time Given Candidate to Respond to Affirmative Offer}

\begin{tabular}{lcc}
\hline Time & Number of Judges & Percent of Judges \\
\hline Immediately & 6 & 7.8 \\
Less than day & 3 & 3.9 \\
1 day & 11 & 14.3 \\
2 days & 11 & 14.3 \\
3 days & 7 & 9.1 \\
4 days & 4 & 5.2 \\
5 days & 2 & 2.6 \\
Several days & 1 & 1.3 \\
1 week & 10 & 13.0 \\
10 days & 1 & 1.3 \\
2 weeks & 3 & 3.9 \\
3 weeks & 1 & 1.3 \\
1 month & 1 & 1.3 \\
No Limit & 16 & 20.8 \\
\hline
\end{tabular}

Source: Derived by author from the Harvard-Chicago 2000 Judge Survey (on file with author).

The Harvard-Chicago Study makes much of the exploding offer phenomenon, both as exemplary of the effects of corrosive competition and as an example of ethical breaches by the judiciary. ${ }^{223}$ Thus, the Study describes a market that gives students "little apparent time to consider multiple options," emphasizing that $25 \%$ of judges required clerks to respond to affirmative offers within twenty-four hours. ${ }^{224}$ The figure is accurate, though the characterization 
is somewhat of an exaggeration. I will discuss the ethics of exploding offers in a context of a market in which time serves as a currency below. Remember, however, that the 1990 Judicial Conference reform of the clerkship market sought agreement to keep offers open for twenty-four hours. Table 2 presents the full data from the survey to inform the discussion.

Table 2 shows that the exploding offer problem is much less serious than might be imagined. According to the Survey, only $7.8 \%$ of judges required students to respond immediately - the truly exploding offer; only $11.7 \%$, in less than 24 hours. Indeed, to the contrary, the Survey suggests that judges generally gave students prolonged time frames to consider offers, suggestive that the level of judicial risk aversion because of competition in the market is less extensive than might be thought. Almost $21 \%$ of judges imposed no time limit on acceptance. Over $41 \%$ gave students a week or longer to respond. ${ }^{225}$

A more interesting question is whether an exploding offer ought to be regarded as an ethical violation in some way. Many markets impose time limitations on the acceptance of offers. E-Bay allows the seller to determine the time limit. Live auctions involve truly exploding offers; the buyer is given seconds to accept or reject at the then-asking price. Markets with time limits for acceptance compel potential buyers to make their search investments in advance and to be prepared with reservation prices at the time the offer is made. Is the judicial clerkship market different in some respect? Imagine a judge who has interviewed a number of students and who finds only small differences in preference as among them. In a context of competition over the timing of offers with other judges, an exploding offer is a rational mechanism for maximizing the chances of a match with one of the preferred set. It is difficult to regard it as unethical. An exploding offer may impose substantial and uncomfortable pressure on a student who did not understand the nature of the market or who, because of coordination difficulties, could not arrange earlier interviews with preferred judges. But is it unfair in some other way?

Perhaps the most controversial finding of the Harvard-Chicago Study as against the market search interpretation relates to students' acceptances of offers in relation to their overall preferences. The Study asked students whether the first offer they received was from their first-choice judge and also whether they accepted that offer. ${ }^{226}$ As mentioned, the Study found that $34 \%$ of students received their first offer from their first-choice judge. ${ }^{227}$ All of those students

225 There may be underreporting here by the judges. The Harvard-Chicago Student Survey did not ask how much time students were given to respond to an offer-because, according to a communication with Professor Jolls, of a legitimate concern that the number of students responding was so much less than the universe that the answers would be misrepresentative. Thus, it is impossible to cross-check the judges' answers.

226 Id. at 823 tbl.9.

227 Id. 
accepted the offer. ${ }^{228}$ The authors do not address the point, but $34 \%$ of the surely several hundreds of applicants ${ }^{229}$ is a high number of first-choice matches. There are only twelve judges on the D.C. Circuit and a handful of other obviously prestigious judges. The statistic showing 34\% of applicants achieving immediate success shows substantial effective sorting. ${ }^{230}$

More debatable, however, is the interpretation of the converse statistic: $66 \%$ of students received first offers from judges other than their first-choice judge. Of this group, $42 \%$ - comprising $28 \%$ of the total student pooldeclined the offer, moving on to other judges. But $58 \%$ of that group-equal to $38 \%$ of the total student sample-accepted that first offer even though not from their first-choice judge, suggesting matching problems. Without further detail, however, it is difficult to evaluate this statistic. First, that $42 \%$ declined their first offer does not suggest market failure. All shoppers decline offers continuously prior to engaging in transactions. ${ }^{231}$ Understanding the decisions of the $58 \%$ who accepted non-first choice offers is more complicated. These decisions may derive from difficulties in coordination. Students submit applications; judges invite some of their applicants for interviews; both try to schedule interviews to maximize mutual matching; but that maximization is difficult. The figure might also reflect to some extent the bird-in-the-hand risk aversion of students that will attend any market with inherent uncertainty about ultimate outcomes. Risk aversion is a real cost. Those students accepting offers from less than first-choice judges must have believed that they were better off doing so, rather than waiting for an offer from their single most-preferred judge.

The statistic, however, might also simply reflect that the first-choices of students and judges did not coincide, surely to be expected in any assortative matching market. It would be interesting to know, for example, how many of the group that accepted non-first-choice offers had succeeded in scheduling interviews with their first-choice judge. That is, the implication of a student accepting an offer from less than a first-choice judge is different if the student had some prospect of interviewing with the first-choice than if the first-choice judge had already rejected or had failed to contact the student at the time of the alternative offer. The Harvard-Chicago Study did not ask that question.

There is some further information, however, available on that point. Although not reported in the Harvard-Chicago Study itself, the fuller data show that, of the set of students who accepted offers from other than their firstchoice judge, $44 \%$ had concluded three or more interviews at the time they

228 Id.

229 There are no data on the number of applicants or applications.

230 I am grateful to Scott Masten for this emphasis.

231 The data show some interesting features of the group who rejected their first clerkship offer. Of the group, $71 \%$ had received another clerkship offer before rejecting the first offer; $56 \%$ received a second offer within two days of the offer they rejected. Derived by author. 
accepted the offer; $72 \%$ had concluded two or more. ${ }^{232}$ Elsewhere, the HarvardChicago Study found that $36 \%$ of applicants received offers after their first interview; a cumulative $59 \%$, after their second; and a cumulative $78 \%$, after their third. ${ }^{233}$ Given those statistics, it is not implausible that the large majority of applicants accepting offers from non-first choice judges saw their prospects of better offers declining and accepted the less-favored offer on that ground.

The Harvard-Chicago Survey did ask the judges what information they found most important to making clerkship decisions. The published Study did not make much use of the answers, ${ }^{234}$ and the question was not framed in a way to fully elucidate the judicial market search process. ${ }^{235}$ The potential responses available in the Survey all related to the candidate's law school performance. Nevertheless, space was provided for a response "Other," in which the surveyed judges could indicate other sources of information useful to the clerkship selection process. ${ }^{236}$ Here, some interesting results appear. Table 3 is a summary of the most frequent other-non-law school-sources of information upon which judges made clerkship selections.

\section{Table 3: Source of Extraneous Information Used by Judges}

\begin{tabular}{lc}
\hline Information Source & Number of Judges \\
\hline Student's life experiences & 22 \\
Personal traits & 9 \\
Public service commitment & 9 \\
Undergraduate professors & 7 \\
\hline
\end{tabular}

Source: Derived by author from the Harvard-Chicago 2000 Judge Survey (on file with author).

One judge provided a more detailed answer: "Tied among top 5 are (a) LSAT scores, (b) life experiences and interests, and (c) college and (if

232 Derived by author.

233 Harvard-Chicago Study, supra note 7, at 814 tbl.2.

234 It reported only judicial rankings of the importance of law review membership. Id. at 887 tbl. A2.

235 The Survey question provided a very limited set of possible responses (plus an "Other"; see text accompanying note 236): law school grades; recommendations from familiar professors, from other professors, from past employers, and from peers; law review membership; law review board position; and writing sample. Id at 808-09. Note that the responses did not include the candidate interview itself, as the authors felt this would have been important to all judges, $i d$. at 809 , (of course the interesting question is, how important?), nor any information regarding candidate performance prior to the candidate's law school career. Moreover, the Survey only asked for ordinal rankings of these information sources, $i d$. at $808-09$, not inquiring about the relative significance of the various information sources (though this approach is surely in keeping with the authors' commitment to ordinal rankings).

236 See id. at 887 tbl. A2 n.b. 
applicable) graduate school grades, and somewhat important are the neatness and coherence of the cover letter., ${ }^{, 32}$

These responses support the point that there are various sources of information besides a student's law school performance upon which to base the offer of a clerkship. In markets in which the time-of-offer currency presses decisions to earlier points, the information base upon which judges make decisions must shift. The student's performance prior to law school becomes of greater relevance than when the clerkship decision can be made at a later period. Thus, the widespread criticism that, in the current clerkship market, the information available is insufficient or inadequate ${ }^{238}$ neglects the informational dynamic of the process. Where, because of the timing of the process, law school information is limited, a judge will resort to other information sources to aid in the evaluation of a student's abilities.

Table 4: Circuit and Years-on-Bench of Early-Offering Judges

\begin{tabular}{lclc}
\hline Circuit & $\begin{array}{c}\text { Number of Early- } \\
\text { Offering Judges }\end{array}$ & Circuit & $\begin{array}{c}\text { Number of Early- } \\
\text { Offering Judges }\end{array}$ \\
\hline First & 3 & Eighth & 8 \\
Second & 6 & Ninth & 7 \\
Third & 5 & Tenth & 2 \\
Fourth & 1 & Eleventh & 2 \\
Fifth & 3 & D.C. & 5 \\
Sixth & 4 & Federal & 2 \\
Seventh & 2 & & \\
\hline
\end{tabular}

\begin{tabular}{lcc}
\hline Years on Bench & $\begin{array}{c}\text { Number of Early- } \\
\text { Offering Judges }\end{array}$ & $\begin{array}{c}\text { Percent of Early- } \\
\text { Offering Judges }\end{array}$ \\
\hline$<6$ years & 14 & 28.6 \\
$6-10$ & 13 & 26.5 \\
$11-15$ & 11 & 22.4 \\
$16-20$ & 4 & 8.2 \\
$21-25$ & 3 & 6.1 \\
$26-30$ & 1 & 2.0 \\
$31-35$ & 3 & 6.1 \\
\hline
\end{tabular}

Source: Derived by author from the Harvard-Chicago 2000 Judge Survey (on file with author).

237 Harvard-Chicago 2000 Judge Survey (on file with author).

238 Harvard-Chicago Study, supra note 7, at 801 ("Decisions must be reached on the basis of extremely limited information."). See generally Oberdorfer \& Levy, supra note 6. 
Finally, who are the early offering judges? The Harvard-Chicago Study characterizes them as judges caught in a rat race that they cannot avoid except through a collective agreement to suppress early interviews and early hiring. The Harvard-Chicago Judge Survey collected only general information about the judges, justifiably in order to preserve anonymity. Table 4, above, however, shows the appellate circuit upon which early-offering judges sit and their approximate years on the bench. Again, the judges indicated in Table 4 are those interviewing and extending offers prior to the receipt of students' third-semester grades.

Again, for the protection of identification, these data are quite general. But they are interesting. They show, first, that early-offering judges are spread fairly evenly among the appellate circuits. They also show that those judges who participate in the early-offer process are the relatively newer judges on the courts, though not entirely newly appointed judges. Of the early-offering set, nearly $30 \%$ had been sitting for less than six years at the time of the survey; over $55 \%$ for no more than ten years. Yet even judges with substantial experience engaged in the early-offer process. Of the early-offering group, over $22 \%$ had been on the bench for over sixteen years, perhaps building on their experience in selecting clerks in the past.

The different approaches of the Harvard-Chicago Study and this paper's focus on market search and the value of information conflict sharply with respect to proposals for market reform. As discussed earlier, the authors of the Harvard-Chicago Study believe that the only feasible reform for the clerkship market is adoption of a centralized matching mechanism, resembling the medical resident match, designed by Professor Roth. ${ }^{239}$ According to such a mechanism, following extensive interviews, judges and students would separately submit ordinal rankings which a computer would sort to maximize ordinal preferences. The authors recognized, however, that many judges would oppose such a mcchanism, and modified their proposal so that the clerkship match would only be mandatory for clerks who wanted to be considered for a subsequent Supreme Court clerkship and for judges who wanted their clerks considered for those clerkships. The authors focused the reform proposal on candidacy for Supreme Court clerkships not because of any concern about the market for Supreme Court clerks; the Justices reported no problems in their clerkship market. Instead, the justification for the proposal was a form of realpolitik: the Supreme Court possesses the authority to mandate a match for their clerks; all other courts lack that authority. The Supreme Court is indifferent to the process of choosing its clerks since they have plenty of qualified candidates. If indifferent, why shouldn't the Court compel the match to help those judges on the circuit courts who would prefer a match? Even with 
a Supreme Court clerk match of this nature, however, the authors expected that there might be cheating. To deter it, they proposed some level of randomization of preferences within the match.

It is not necessary in this paper to take any position on market reform. It is perhaps worthy of note, however, to indicate the extent to which the reforms proposed by the Harvard-Chicago Study are inconsistent with the ambition of improving welfare by increasing information in the market. As mentioned, centralized matching mechanisms are designed to maximize ordinal preferences. By definition, ordinal rankings suppress differences in intensity of preference as between the rankings. There are no widely accepted means of registering strength of preference within any ranking. ${ }^{240}$ As a consequence-a well-accepted proposition in the public choice literature-ordinal maximization does not guarantee the maximization of aggregate preferences. ${ }^{241}$

In contrast, markets maximize aggregate preferences by allowing intensity of preference to be readily registered. The most common medium for registering intensity of preference is price-the highest bidder is the person who most wants the product or service-but other terms of trade can serve the same purpose. In the context of the clerkship market where, as has been discussed, price signals are suppressed, time-of-offer serves as a market-clearing mechanism to allow judges with higher intensities of preference for clerks to bid them away from judges whose intensities of preference are lower. The centralized matching mechanism, of course, extinguishes this medium.

Perhaps most surprising of the Harvard-Chicago reform proposals is the response to the prospect of cheating on the proposed clerkship match. The cheating the authors fear consists of agreements or understandings between judges and clerk-applicants entered prior to the match over the rankings that each will submit. Thus, they are concerned that a judge will meet and get to know a student - and the student, the judge - and mutually agree to submit the other's name as their first choice, violating the confidentiality rule of the matching mechanism. To prevent such behavior, they propose that, if detected in sufficient volume, "a small degree of randomization" could be introduced into the match "to destabilize the informal understandings.",242

The normative characterization of understandings between judges and clerk-applicants as "cheating" exposes the peculiar regulatory impulse that lies beneath the proposal. Pre-match agreements between judges and students (or, in the medical resident match, between students and hospitals) are a form of

240 As an example, one judge may prefer applicant one far more than applicant two and be largely indifferent as between applicants three and four, with a slight preference for three. A second judge may find applicants one and two largely indistinguishable, but prefer two far more than three; and so forth. In a highly plausible context of this nature, maximizing ordinal matches cannot be guaranteed to maximize aggregate welfare.

241 See, e.g., 3 Dennis C. MUEller, Public Cholce 591 (2003).

242 Harvard-Chicago Study, supra note 7, at 882-84. 
cheating only in the sense of a violation of those rules of the match that seek to eliminate all non-match agreements in order to maximize control over the employment process by the match. But the authors strive to achieve this goal by adopting a set of rules that would seem to frustrate the objectives of the process itself. That is, the most basic goal here is to facilitate the matching of a judge and a student who want to work together. The authors' proposal, however, regards the mutual agreement of a judge and a student to work together as "cheating." Moreover, the notion that an effective means of deterring such behavior is to randomize the match results turns the process entirely on its head. Can it be defended that, to preserve the integrity of a mechanism adopted to improve the matching of the preferences of judges and clerks, the matches should be randomized?

Finally, in light of the recommendations of Judge Wald and Judge Oberdorfer to explicitly adopt the medical matching mechanism ${ }^{243}$ and of the recommendation of the Harvard-Chicago Study to adopt a modified medical match, some further attention might be given to the consequences of efforts to constrain the timing of the judicial clerkship market. First, I have earlier referred to the "wealth effect" character of the availability of time-of-offer as a currency in the market, giving certain judges willing to invest in techniques of prediction power in the market that they might not otherwise possess. Efforts to constrain timing, either by agreements such as on a March 1 or April 1 hiring date, by the current deferral of clerkship applications until after Labor Day or, surely, by adoption of a centralized matching mechanism, obviously reduce or eliminate that "wealth effect." Who benefits from postponed or centralized matching? In the clerkship market idealized by the HarvardChicago Study, among others, in which after an extensive series of interviews, students and judges armed with comprehensive information about the full judge and clerkship pool make choices among potential options, which judges are most likely to benefit?

The benefit most commonly invoked of postponed decision-making in the clerkship market is the avoidance of competition; thus, the many criticisms of the alleged "frenzied" or "chaotic" character of the market, surely the tone of the Harvard-Chicago Study. Undoubtedly, many judges abjure market competition; perhaps that was one of the attractions to them of leaving practice and becoming a judge. It seems evident, however, that the judges most likely to benefit from delayed choice or centralized matching are the relatively more attractive judges: those judges whose clerkships are most desired by the largest number of clerkship candidates. Postponing the clerkship selection process allows these judges to survey the entire pool of applicants and pick off the very 
best of them for themselves. Postponing the market is also likely to most benefit the most-qualified applicants.

Prominent judges are not disabled by an early-offer process; surely not, a prestigious clerkship remains a prestigious clerkship. But to guarantee that they secure the most able clerks, these judges have to compete with their less prominent colleagues, compelling these prominent judges to make decisions based upon less information about applicants than they would otherwise prefer. To less prominent judges, entering the early-offer market for clerks resembles prospecting: if energy is spent wisely, there may be great returns otherwise unavailable. To relatively prominent judges, in contrast, the efforts of the less prominent in instigating the early-offer process must surely be an annoyance. When some judges begin interviews at early points or extend clerkship offers, other judges who also want the best clerks must compete as well. It is surely more difficult to identify those applicants who will make the most productive clerks early in the process rather than late. This is the burden imposed upon the relatively prominent judge by the commencement of the competition of the early-offer process. It is no wonder that many of the most able and prominent judges in the country have endorsed increasing regulation of the timing of the clerkship market. ${ }^{244}$ Their advocacy, however, and their distaste of the earlyoffer clerkship market may only be a variation of Hicks' famous aphorism, that the best of all monopoly returns is a quiet life. ${ }^{245}$

The second principal effect of constraints on market timing such as the current application moratorium is to compress match-making into a substantially shorter time period than would otherwise prevail. This compression can be predicted to increase the premium on tactical interview scheduling, thus reducing the number of interviews that applicants and judges can effectively undertake. This compression will also increase the costs to judges of affording applicants extensive time to consider accepting an offer. Thus, the exploding offer phenomenon is likely to increase. ${ }^{246}$ The compression will provide more choices to more prominent judges; less, to the less prominent. It cannot, in any general sense, be predicted to increase the aggregate effectiveness of judge-clerk matchmaking.

244 This characterization may be unfair because the most able judges are usually likely to be the most prominent promoters of any reform recommendation. I also do not mean to suggest any self-serving behavior here. To my knowledge, this wealth effect analysis has not before been part of the literature.

245 J.R. Hicks, Annual Survey of Economic Theory: The Theory of Monopoly, 3 ECONOMETRICA 1, 8 (1935).

246 The Harvard-Chicago Study, of course completed prior to the moratorium, predicted similar effects. Harvard-Chicago Study, supra note 7, at 862-68. 


\section{The Curious Case of Yale Law Schoot ${ }^{247}$}

As perhaps a footnote to the discussion of the clerkship market, it is interesting to address the role and experience of Yale Law School in the clerkship reform movement and in the market itself. Yale is apparently unique among law schools in having adopted a policy according to which all students' first semester courses are ungraded. This policy means that Yale students receive fewer law school grades-one semester fewer-than students at all other law schools. The significance of the policy to the clerkship market is that, as the clerkship market commences at earlier and earlier times in students' law school careers, the relative law school grade deficiency of Yale students increases. Where the market begins at the end of law students' third semester, Yale students will have two semesters of law school grades on record; students at all other schools, three semesters-one and a half times the Yale amount. Where the market begins earlier, at the beginning of the students' second year, Yale students will have one semester of law school grades; students at other schools, two semesters-twice the Yale amount. ${ }^{248}$

The Yale Law grade disadvantage is one of many reasons that two recent Deans of Yale Law School, Guido Calabresi and Anthony T. Kronman, have strenuously and effectively advocated reforms that would serve to delay commencement of the market. Dean Calabresi, as has been discussed earlier, led an organization of law deans to support a March 1 (of the student's second year) benchmark date; later, as a Judge on the Second Circuit, he joined Judge Becker and Justice Breyer in their advocacy of the "March 1 Solution."249 Dean Calabresi's successor, Dean Kronman, was equally ardent in organizing the academy to constrain commencement of the market.

The Harvard-Chicago Study does not address the impact of the market, of unraveling in the market, or of market reforms on comparative law school success, but it does report appellate clerkships by school for the 2000 clcrkship year. Table 5, below, reproduces the Study's results in Columns 1 through 3. Column 1 presents the U.S. News \& World Report ranking of law schools for the year 2000 , roughly in order of ranking. ${ }^{250}$ Column 2 presents the number of appellate clerks during the 2000 term from each school; Column 3, the

247 The conflicted loyalties here are overwhelming.

248 The deficiency is not quite so dramatic because Yale students will typically seek recommendations from one-though typically, in my experience, not more than one-of their first semester teachers, providing the equivalent of a grade.

249 See the discussion, supra text accompanying notes 58-64.

250 The Harvard-Chicago Study elevated the University of Chicago which, though ranked sixth by U.S. News \& World Report, appears as the fourth school on the list. It did so because its survey sampled Chicago students given that one of its co-authors is affiliated with the University of Chicago. 
school's student class size; ${ }^{251}$ Column 4 (derived by the author), the percentage of clerks within each law school's class. The year 2000 was one in which the clerkship market was completely unregulated. The Judicial Conference withdrew the March 1 benchmark in 1998. Subsequent reform efforts had proven unavailing.

Table 5: Federal Appellate Clerkships by Law School Class

\begin{tabular}{lcccc}
\hline & $\begin{array}{c}(1) \\
\text { U.S. News } \\
\text { Ranking }\end{array}$ & $\begin{array}{c}\text { Number of } \\
\text { Clerks }\end{array}$ & $\begin{array}{c}(3) \\
\text { Size of Class }\end{array}$ & $\begin{array}{c}(4) \\
\text { Clerks as \% } \\
\text { of Class }\end{array}$ \\
\hline Yale & 1 & 45 & 192 & 23.44 \\
Stanford & 2 & 16 & 182 & 8.79 \\
Harvard & 3 & 56 & 552 & 10.14 \\
Chicago & 6 & 26 & 188 & 13.83 \\
NYU & 4 & 21 & 443 & 4.74 \\
Columbia & 5 & 22 & 389 & 5.66 \\
Michigan & 7 & 13 & 356 & 3.65 \\
Berkeley & 8 & 13 & 282 & 4.61 \\
Virginia & 9 & 17 & 363 & 4.68 \\
Cornell & 10 & 7 & 182 & 3.85 \\
Duke & 10 & 10 & 214 & 4.67 \\
Northwestern & 12 & 10 & 217 & 4.61 \\
Penn & 13 & 4 & 252 & 1.59 \\
Georgetown & 14 & 20 & 587 & 3.41 \\
Texas & 15 & 4 & 470 & 0.85 \\
UCLA & 16 & 10 & 319 & 3.13 \\
USC & 17 & 1 & 203 & 0.49 \\
Vanderbilt & 18 & 4 & 187 & 2.14 \\
Minnesota & 19 & 2 & 235 & 0.85 \\
Wash. \& Lee & 20 & 3 & 122 & 2.46 \\
\hline
\end{tabular}

Source: Harvard-Chicago Study, supra note 7, at 888 at tbl. A3 (footnotes omitted). Numbers in Column 4 derived by author (i.e., Col. 2/Col. 3).

251 The class sizes in Table 5 are approximations. Like U.S. News \& World Report, the Harvard-Chicago Study determined class size by dividing the total number of students at each school by three. This calculation is probably a close approximation, but is an approximation. 
As Table 5 shows, Yale Law School was ranked number one in the country in the year $2000 .^{252}$ Table 5 also shows, however, that in the year 2000, Yale Law School placed a far higher percentage of its graduating students in appellate clerkships than any other law school. Column 4 shows that $23.44 \%$ of the Yale graduating class secured appellate clerkships. In comparison, Stanford, the second-ranked law school, placed 8.79\%; Harvard, third-ranked, placed $10.14 \%$, less than half of Yale's; and Chicago, the sixthranked, placed $13.83 \%$, substantially greater than its fourth- and fifth-ranked competitors, NYU and Columbia, but again less than two-thirds of Yale's placement.

These results should seem surprising. In a time-the year 2000characterized by extreme clerkship market unraveling (again the Judicial Conference abandoned all benchmark dates in 1998)-Yale students should be expected to be at an increasing disadvantage because of the absence of first semester grades. ${ }^{253}$ What can account for their extraordinary comparative success in the clerkship market?

One explanation is that Yale Law School is just a much superior school to all others. But this explanation of differential clerkship success is implausible. $^{254}$ The U.S. News \& World Report study, besides providing ordinal rankings, provided what it called an "Overall Score" in which the firstranked school scored 100; the lesser-ranked, some fraction. ${ }^{255}$ For the year 2000 , Yale as the first-ranked scored by definition $100 .^{256}$ Stanford, the secondranked, scored 92; Harvard, the third-ranked, scored 91; Chicago, the sixthranked, scored $84 .^{257}$ However skeptical we might be about the approximate nature of U.S. News \& World Report's' ranking methodology, these rankings would not support the empirical fact that Yale Law School placed 2.67 times the fraction of its graduating class in appellate clerkships as second-ranked Stanford, 2.31 times the fraction as third-ranked Harvard, and 1.69 times that of the (over-achieving or under-rated ${ }^{258}$ ) University of Chicago. Again, what accounts for Yale Law School's comparative success?

252 The U.S. News \& World Report law school rankings have been quite stable over the past decade. See, e.g., Law Schools, U.S. NEwS \& WorLD REP., Mar. 21, 1994, at 72; Schools of Law, U.S. NEWS \& WORLD REP., Mar. 2, 1998, at 78; Schools of Law, U.S. NEWS \& WORLD REP., Apr. 9, 2001, at 78 .

253 The Harvard-Chicago Study also predicted that Yale Law students would suffer a disadvantage in the market because of the grade deficiency. Harvard-Chicago Study, supra note 7, at 861 .

254 See supra note 247.

255 Methodology, U.S. NEwS \& WORLD REP., Apr. 10, 2000, at 74.

256 Schools of Law, U.S. NEws \& WORLD REP., Apr. 10, 2000, at 73; Methodology, supra note 255 .

257 Schools of Law, supra note 256.

258 I am a devoted graduate of the University of Chicago Law School. 
A focus on market information and the determinants of market search suggests an answer. As the nation's first-ranked law school, Yale is likely to receive applications from many of the most productive applicants in the country as measured by available indicia of performance prior to law school. If it admits the most productive of those applicants, its entering law school class will, at least by the record, comprise the most able-again, record-wise- of any entering class in any law school.

As unraveling in the market for judicial clerkships presses the market to earlier and earlier times, the relative importance of a candidate's pre-law school record, as compared to the law school record, increases. This is a simple economic point. As there is less information about law school performance, information about performance prior to law school gains greater importance. This means, however, that unraveling benefits Yale Law School students because unraveling marginally shifts the information base that is significant for the clerkship decision from law school performance-for which there is uniformly less information-to pre-law school performance where Yale students possess an advantage.

\section{Table 6: Proportion of Yale Law School Class Obtaining Appellate Clerkships}

\section{(1)}

Number of App.

\begin{tabular}{cccc} 
Year & Clerks & Size of Class & Percent of Class \\
\hline 1990 & 40 & 161 & 24.84 \\
1991 & 43 & 164 & 26.22 \\
1992 & 44 & 169 & 26.04 \\
1993 & 55 & 172 & 31.98 \\
1994 & 56 & 184 & 30.43 \\
1995 & 48 & 178 & 26.97 \\
1996 & 46 & 168 & 27.38 \\
1997 & 61 & 203 & 30.05 \\
1998 & 58 & 159 & 36.48 \\
1999 & 64 & 176 & 36.36 \\
2000 & 65 & 172 & 37.79 \\
2001 & 68 & 180 & 37.78 \\
\hline
\end{tabular}

Source: Derived by author from data from Yale Law School Career Development and Registrar's Offices and the JUDICIAL YELLOW BOOK, various years (on file with author). ${ }^{259}$

259 Note that these numbers differ from the numbers in the Harvard-Chicago Study. I am confident that my numbers are more accurate. The Harvard-Chicago Study took its clerkship numbers 
Some further research is suggestive on this topic, though more work needs to be done. Table 6 above presents Yale's appellate clerkship experience since 1990. Column 1 presents the number of appellate clerks in each graduating class; Column 2, class size; Column 3, the percentage of the class obtaining appellate clerkships. ${ }^{260}$

Table 6 shows (in Column 3) that the percentage of each Yale Law School graduating class obtaining appellate clerkships increased steadily from 1990 to 1993 (from 24.84 to $31.98 \%$ ), dropping slightly in 1994 (to $30.43 \%$ ). In 1994, it will be remembered, the Judicial Conference joined by major law schools led by Yale's Dean Guido Calabresi, introduced the March 1 benchmark date, constricting earlier commencement of the clerkship market. The March 1, 1994 date would control clerkships for the 1996 year. Column 3 shows that Yale's class percentage dropped significantly in 1995 (to $26.97 \%$ ) for reasons not entirely clear, and in 1996 (at 27.38\%) was still about 3\% less than in 1994 and nearly $5 \%$ less than in 1993. According to casual surveys of the market, however, after 1994, the benchmark was increasingly ignored and, of course, was abandoned entirely in 1998. Thus, the market became increasingly unregulated; the clerkship market began at progressively earlier times, seemingly to the disadvantage of Yale students. Over the same period, however, Yale's percentage-of-class placed in appellate clerkships successively rose to its highest point in 2001 (at $37.78 \%$ ), over ten percentage points higher than the 1996 figure.

I do not wish to make too much of these data. ${ }^{261}$ They are suggestive, however, of the basic analysis. In evaluating any market-including the market for judicial clerks - it is essential to concentrate upon marginal changes in the determinants of market search. A constraint on the timing of market transactions shifts the information base upon which market participants make decisions so that information from later periods gains a marginal advantage over information from earlier periods. In contrast, the elimination of that constraint, in a context in which time-of-offer becomes a currency, leads judges

only from the Judicial Yellow Book, which they admit to be incomplete, Harvard-Chicago Study, supra note 7, at 809; they derived class size by dividing total law school enrollment by three which will give a larger number where it includes graduate students who seldom participate in the clerkship market. My class size numbers-from both Yale's internal files and Thomas Obhof's efforts, supra note 260 - count only JDs. All clerk/class figures are likely to be incomplete over some range because some students will accept clerkships at some distance after law school.

260 I am grateful to Marilyn Drees and Judith Calvert of Yale Law School's Career Development and Registrar's Offices for providing these data. I am also grateful to Thomas Obhof who laboriously tracked the law school attended by every appellate clerk for 1990-2001. He uncovered many from Yale unknown to the Career Development Office.

261 Judge Posner has suggested a different reason for the relative success of Yale Law students: that Yale students are much less interested in law practice than students at other major law schools and, thus, find clerking more attractive as a post-graduate job. This hypothesis, of course, does not address changes in relative Yale applicant success across years. 
to rely on information generated at earlier periods in a student's career. The very high rate of success of Yale students in the clerkship market seems to also confirm the skepticism that it is useful to claim, at any point in the clerkship selection process, that judges possess "inadequate". information upon which to select clerks. The concept of information "inadequacy," again, is foreign to the economic approach, except where no clerkship offers are extended. If no judge has extended an offer, the information base is inadequate; conversely, where judges are confident enough to extend offers, the information base is adequate enough. More precisely, the timing of the clerkship market may shift to earlier times where judges can obtain sufficient information about a candidate to justify an offer through shifting the information base to pre-law school performance.

This analysis suggests the possibility that the advocacy of the Deans of Yale Law School to constrain the clerkship market to later periods in students' law school careers may not benefit Yale students on the whole. The effect is not likely to be uniform across students. Some students may appear relatively more attractive in the broader clerkship pool with another semester of law school grades; other students may be relatively more attractive with fewer law school grades and greater attention to college or other pre-law school performance. The Yale Law School clerkship pool on the whole may well appear relatively more attractive when less attention is given to law school performance and more given to the credentials upon which they were admitted to Yalc.

This analysis also suggests a future empirical test of the approach. As mentioned, this past year the federal appellate judiciary agreed on a one-year moratorium on the submission of clerkship applications from the 2004 law school class, postponing the beginning point of the market until the first semester of a student's third year. Given that most believe that the moratorium proved successful, Yale students should do relatively more poorly in competition because the moratorium will have the effect of shifting the information base away from the students' pre-law school record towards law school, reducing the Yale advantage of earlier years. Data are not yet available to test the hypothesis.

\section{A Reanalysis of Unraveling in the Other Markets Identified by Professor Roth}

This Part employs the market search approach to reevaluate the many other markets identified by Professor Roth as suffering unraveling.

The analysis of this paper differs from Professor Roth's in several respects. First, by emphasizing the significance of the costs and benefits of information acquisition as determinants of the timing of market transactions, the analysis is highly skeptical of the concept of an "optimal" transaction time. Second, and relatedly, by viewing market timing as an issue of information acquisition, the analysis implies that efforts to regulate market timing are likely to be 
differentially harmful to participants in the market, in particular to those willing to invest in search to benefit from an early commitment. ${ }^{262}$ Third, the analysis adopts a much narrower definition of market unraveling. There are many contexts in which parties gain information to inform potential future transactions-such as audition electives for surgeons or summer internshipsthat are not usefully considered as market aberrations. They are expected characteristics of markets in which the future value of the transaction is uncertain and information is costly but obtainable through on-the-job experience.

This is not to dismiss the concept of market unraveling, though perhaps the pejorative connotation it gives to comparatively early market commitment commends a different term. Professor Roth's three sources of the practiceinstability in matching because of transaction congestion; risk aversion of the parties; and differential participant market position-are descriptively accurate in many contexts. For example, in the market for judicial clerks, judges and clerks are led to enter early agreements because both are averse to the risk of obtaining a less favorable clerk or clerkship at a later date, something of an amalgam of Professor Roth's risk aversion and differential market position explanations. $^{263}$

Nevertheless, however descriptively accurate, the Roth explanations constitute something less than a theory of unraveling. There exist many markets in which participants can be expected to be averse to the risk of differential market position at later dates that seem not to be characterized by any form of unraveling. As mentioned, Professor Roth concedes that many entry-level labor markets do not suffer unmanageable unraveling-entry level MBAs and business school marketing professors. ${ }^{264}$ Many other labor markets could be identified that are also relatively free of unraveling: the markets for high school and college graduates, among others. It is implausible that there is no aversion to the risk of future placement in any of these markets.

To my mind, there are two separate phenomena to which Professor Roth's work has alerted us that explain virtually all of his examples of true unraveling. One is a market phenomenon; the second, a regulatory

262 The emphasis on the significance of market information also implies that it reduces aggregate welfare, a fortiori, to enforce market regulation by reducing the information available to market participants such as the Harvard-Chicago Study's recommendations of "[m]aking it more difficult for judges to gather information..." and "limiting the information available to judges," Harvard-Chicago Study, supra note 7, at 867 (recommending a "palliative" to help enforce set start dates)-or otherwise impairing market matching-such as the Study's recommendation of randomizing matches to deter pre-match agreernents in their modified medical match proposal, $i d$. at 883-84.

263 I am not certain that there is any useful sense in which Professor Roth's risk aversion and differential market position explanations can be considered separately. Differential market position as between time $T$ and time $T$ - I will generate risk aversion.

264 Roth \& Xing, supra note 11, at 1013-14. 
phenomenon. They are related because they both involve constraints in some form on the operation of market forces.

The first and, I believe the most interesting, phenomena in the Roth examples are markets in which time-of-offer is employed as a currency in the market transactions themselves. Professor Roth does not focus on time-of-offer as a currency, except to consistently recommend a matching mechanism in order to suppress it. This paper, instead, proposes an explanation. As explained above, time-of-offer emerges as a prominent currency where there are restrictions in the market on the use of alternative terms of trade that might otherwise serve the market clearing function. In markets in which the terms of trade are truncated, a chief way for the parties to express their mutual intensities of preference in the context of future transaction uncertainty is through time-ofoffer.

The second phenomenon that explains other of Professor Roth's market examples derives from market regulation. Many of the Roth examples show, not unfettered market processes, but participant responses to market regulation. The examples that correspond to Professor Roth's first unraveling explanation-matching instability at the optimal market transaction time because of transaction congestion - derive, not from some characteristic inherent to the underlying markets, but from forms of market regulation that constrain transactions to some "optimal" time. What Professor Roth calls "unraveling" are efforts to evade those regulations.

Though different, the two phenomena are related in that they both appear in contexts in which price or other terms of trade have been subjected to some constraint. Transacting at a time different from what might be expected according to an idealized notion of the optimal market time is a means of overcoming that price restraint. Thus, again, far from representing a market imperfection or a market failure, these actions represent market processes in force to overcome artificial market constraints.

Below is a list of the markets identified by Professor Roth as possessing timing problems with a short description of the respective problem. These markets are listed in increasing order according to Professor Roth's four market stages. Note that, as has been mentioned, Professor Roth's four stages do not correspond to market phenomena. They are stages of differential levels of regulation: stage 1 -an unregulated market; stage 2-attempts to establish uniform dates; stage 3-adoption of a centralized clearing procedure, such as the medical match; and stage 4-adoption of a centralized matching procedure, but with cheating requiring further regulation. ${ }^{265}$ Because of the focus on the nature of the regulation, the unraveling phenomena are not always clearly described. 


\section{Markets with Unraveling or Controls on Transaction Timing}

1) Federal court clerkships-substantial unraveling through early offers; many proposals to regulate; current one-year moratorium; ${ }^{266}$

2) First year associates in American law firms-unraveling by the offer of summer associate positions; ${ }^{267}$

3) Graduating MBAs and marketing professors-occasional early offers, but no serious unraveling; ${ }^{268}$

4) Humanities and social science graduates in Japan-concerns over early offers and agreements between employers' organizations regarding employment periods; ${ }^{269}$

5) Clinical psychology interns-proposals for uniform employment dates but no detailed evidence of unraveling; ${ }^{270}$

6) Medical residents in the U.S. and other first-year medical positions-substantial unraveling followed by adoption of the medical match, although cheating on the match occurs through audition electives; ${ }^{271}$

7) Fraternities and sororities in U.S. colleges-unraveling in member recruitment: the "rush,;",72

8) Articling law students in Ontario - alleged unraveling, followed by adoption of a matching mechanism, but with cheating on the mechanism through student summer internships; ${ }^{273}$

9) College and professional athletes-no unraveling, but adoption of fixed recruiting times and centralized drafts; ${ }^{274}$

10) Academic markets for mathematicians, biologists and chemistsunraveling through initial appointments in post-doctoral degree positions prior to securing faculty positions. ${ }^{275}$

11) Postseason college football bowls-unraveling through early offers to teams followed by centralized bowl assignments; ${ }^{276}$

12) Medieval commodity markets-unraveling in the form of premarket period transactions; ${ }^{277}$

Roth \& Xing, supra note 11, at 1000-05.

267 Id. at 1004-07.

268 Id. at 1013-14.

269 Id. at 1015-16.

270 Id. at 1016-18.

271 Id. at 998-1000, 1018-19, 1020-24.

272 Id. at 1019-20.

273 Id. at 1024-25.

274 Id. at 1025-26.

275 Id. at 1026-27.

276 Id at 1007-13.

277 Id. at $1027-28 \&$ n. 68. 
13) Chicago Board of Trade-prohibition on member sales of in transit grain at other than at a fixed price, similar to other restrictions serving to create the market. ${ }^{278}$

Note that, in various of these markets, the purported problem consists of an institutional structure or practice that allows the potential employer to gain additional information about the worker (and, possibly, the worker to gain information about the employer) prior to entering the final employment transaction. Thus, in 2) above, first year law associates are hired typically after serving the firm for some months during a preceding summer, a position similar to 6), audition electives for surgeons. Somewhat differently, in 10) above (and in many other scientific areas), recent PhDs gain experience in research positions following completion of their doctoral degree, but prior to obtaining an academic faculty job. Professor Roth characterizes these activities as "unraveling" because they represent interactions that might lead to a market transaction - the employment hire-prior to some defined time. But as discussed, I do not view this definition of unraveling as helpful. Shopping prior to purchase is not unraveling and is to be expected in some form in every market.

In those markets in which there appears evidence of unraveling, ${ }^{279}$ I believe that most of the practices can be understood as deriving from restrictions on the availability of price as a currency to clear the market, though in two separate contexts: the first, where time-of-offer becomes a currency; the second, where the timing of market transactions becomes a means of evading some form of market regulation.

\section{Time-of-offer currency markets}

1) Federal clerkships

6) Medical residents

7) Fraternity-sorority rush

8) Articling in Ontario

9) College and professional athletes

11) College football bowl games
Transaction timing to evade regulation

12) Medieval commodity markets

13) Chicago Board of Trade

$278 \quad$ Id. at 1028.

279 In various other of Professor Roth's examples, it is not evident that there is any unraveling of import, though many involve discussions of regulation of market timing for reasons that are not apparent from the description: 3) MBAs; 4) Japanese university graduates; 5) clinical psychologists. Perhaps more study of these markets would clarify. 


\section{Time-of-Offer Currency Markets Reviewed}

This Section discusses those of Professor Roth's markets in which the unraveling relates to the use of time as a currency to clear the market. The hypothesis of the paper is that time becomes a currency where there are restrictions on other terms of trade.

\section{a. Federal clerkships}

A lengthy discussion of federal clerkships is unnecessary here. As explained in detail above, ${ }^{280}$ because clerkship salaries and benefits are set by Congress, there are limited effective terms with which judges and clerks can express intensity of preference in order to clear the market. Time-of-offer serves that function for judges and clerks averse to the risk of constrained choices at later market times.

\section{b. Medical residents ${ }^{281}$}

In the U.S., following four years of medical school, students apply for a residency position with a hospital, often with an announced medical specialty. As has been mentioned, much of Professor Roth's work has been devoted to organizing centralized matching mechanisms for residency positions of this nature. ${ }^{282}$ The first adoption of a centralized matching mechanism for general residents followed several years in which the medical resident market was characterized by serious unraveling-where time-of-offer served as a currency. As Professor Roth describes the pre-match market,

Appointment dates unraveled from about the turn of the century until 1945 , so that by 1944 medical students were arranging their postgraduate employment as interns two years in advance of graduation. Starting in 1945 a regime of uniform dates and times were introduced, and it was enforced with the help of an apparently successful refusal of medical schools to provide information [to hospitals] prior to a specified date. This succeeded in reversing the unraveling, and appointment dates were first moved back into the junior year, and then into the senior year of medical school. However, in 1945 the

280 See supra Section II.A.

281 I have been aided in this analysis by discussions as a consultant with a group of attorneys that has filed an antitrust suit against various U.S. medical associations and the NRMP. I express no view here on the merits of the litigation.

282 In addition to Roth \& Xing, supra note 11, see Roth, Medical Interns, supra note 11; Alvin E. Roth, New Physicians: A Natural Experiment in Market Organization, 250 SCIENCE 1524 (1990); Alvin E. Roth \& Elliott Peranson, The Redesign of the Matching Market for American Physicians: Some Engineering Aspects of Economic Design, 89 AM. ECON. REV. 748 (1999); Alvin E. Roth \& Xiaolin Xing, Turnaround Time and Bottlenecks in Market Clearing: Decentralized Matching in the Market for Clinical Psychologists, 105 J. POL. ECON. 284 (1997). 
period specified for offers to remain open was ten days, and this interval shrunk rapidly, so that by 1949 a 12 -hour period was rejected as too long, and no minimum duration at all was specified. The congestion in the market, with its collateral missed opportunities and hasty agreements which were later sometimes not honored, led to the adoption, in 1952, of a (voluntary) centralized market-clearing procedure of the matchmaker variety. ${ }^{283}$

Table 7: Range of Salaries, 1st Year Graduates: Medical, Law, 2001

\begin{tabular}{llrl}
\hline & \multicolumn{2}{c}{ Medical School Graduates } & \\
Region & 25 th $\%$ & 75 th $\%$ & Range \\
\hline Northeast & $\$ 35,930$ & $\$ 39,401$ & $\$ 3,471$ \\
South & $\$ 33,445$ & $\$ 35,300$ & $\$ 1,855$ \\
Midwest & $\$ 35,353$ & $\$ 36,908$ & $\$ 1,555$ \\
West & $\$ 32,700$ & $\$ 35,220$ & $\$ 2,520$ \\
\hline
\end{tabular}

Law School Graduates

\begin{tabular}{lrrr} 
State & 25 th $\%$ & 75 th $\%$ & Range \\
\hline New York & $\$ 47,500$ & $\$ 125,000$ & $\$ 77,500$ \\
Georgia & $\$ 45,000$ & $\$ 100,000$ & $\$ 55,000$ \\
Ohio & $\$ 40,000$ & $\$ 81,500$ & $\$ 41,500$ \\
California & $\$ 54,000$ & $\$ 125,000$ & $\$ 71,000$
\end{tabular}

Sources: Derived by author from 2000 AAMC SURVEY OF HOUSESTAFF STIPENDS, BENEFITS AND FUNDNG, tbls.6, 8, at http:/www.aamc.org/hlthcare/coth-hss/2000hss/hss00_6.htm, http://www.aamc.org/hlthcare/coth-hss/2000hss/hss00_8.htm (last visited Feb. 16, 2001); ${ }^{284}$ NALP, Starting Salaries: What New Law Graduates Earn, Class of 2001, at 10.

Thus, since 1952, medical residencies have been allocated by means of a matching program according to which both residents and hospitals, following interviews, submit rank ordered preferences to a centralized organization which, on a set date, matches them according to the respective highest rankings. This matching program is designed to eliminate the early-offer competition characteristic of markets such as judicial clerkships and is often justified as necessary given the large number of medical graduates and the equally large number of hospitals to which they are applying.

It is the hypothesis of this paper, in contrast, that the existence of earlyoffer competition in markets such as medical residencies derives from the

283 Roth \& Xing, supra note 11 , at 999.

284 The 2000 survey is no longer available on AAMC's new survey website, http:/www.aamc.org/data/housestaff/start.htm (last visited Nov. 16, 2004); however, the current website provides contact persons for inquiries regarding the surveys. 
limitations on price or other market mechanisms to clear the market. ${ }^{285}$ To examine the hypothesis, Table 7 above compares the salary range for first-year graduates in medicine and in law. It shows, for the year 2001, the 25th and 75 th percentile starting salaries for medical school graduates by region and for law school graduates by state within the respective regions. ${ }^{286}$ Each year, more students graduate from law than from medical schools. In 2000, 38,152 students graduated from U.S. law schools, nearly two and one-half times the 15,286 who graduated from U.S. medical schools. ${ }^{287}$ Neither Professor Roth nor any other commentator (to my knowledge) has suggested that the market for law school graduates is characterized by the use of time-of-offer as a currency.

Figure 1: Range of Salaries, First-Year Medical Residents, 1952-2002

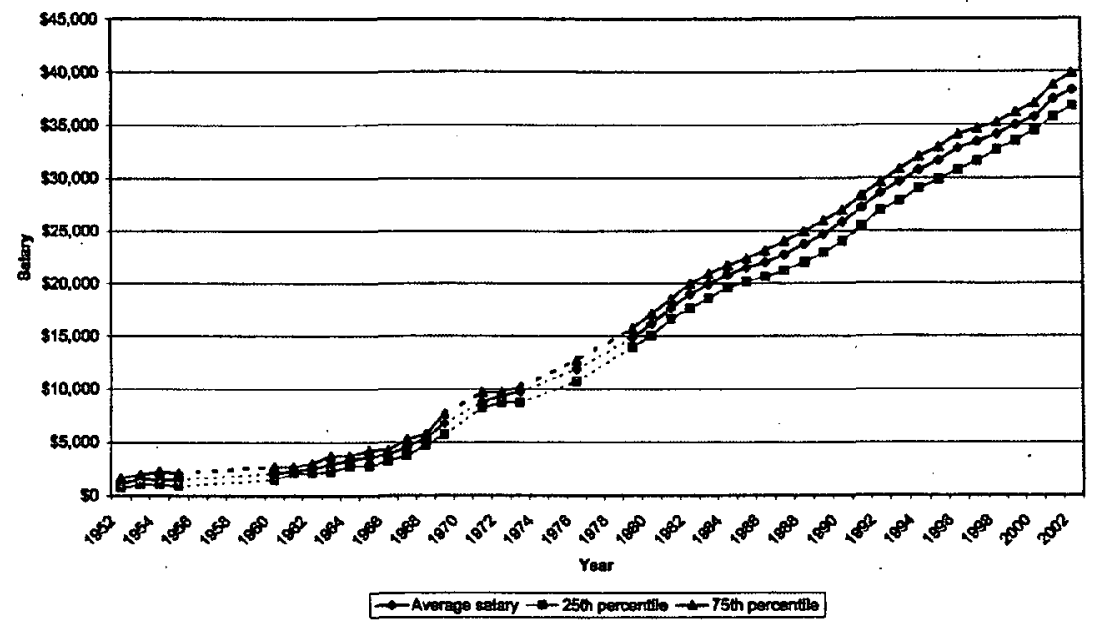

For 1952-1978, data derived from J. AM. MED. ASS'N, various years. For 1979-2002, data derived from COUNCIL OF TEACHING HOSPS. \& HEALTH SYS., ASS'N OF AM. MED. COlls., SURVEY OF HOUSESTAFF STIPENDS, BENEFITS AND FUNDING, various years (data on file with author).

It is apparent from Table 7 that the range of available salaries both within geographic regions and across regions is dramatically greater for law graduates than for medical graduates (indeed, for all four geographic comparisons, more than twenty times greater). Table 7 , of course, only presents salary data for one

285 Ulrich Kamecke has hypothesized that the need for a centralized matching mechanism for medical residents derives from insufficiently flexible wages. Kamecke, supra note 16 .

286 The two data sources for medical school and law school graduate salaries do not match and cannot be made to match given the published data-the medical data are given by region; the law data, by state. I selected as representative large states within each region.

287 STATISTICAL ABSTRACT: 2002, supra note 186, at 178 tbl.281. 
year. Although I have not been able to obtain comparable time-series data for first-year law graduates, Figure 1 shows the range of first-year medical resident salaries since 1952. As is evident, resident salaries have been restricted within an extraordinarily narrow range now for five decades.

Accelerated offers ane not unknown in the market for law school graduates which law school placement offices attempt to regulate. First-year associate salaries are not entirely flexible, but appear to be constrained within levels by type of firm, expected workload and city. These constraints may explain the use of time-of-offer for some applicants.

The narrow range of salaries available for medical residents explains why time-of-offer becomes a dominant currency in the market for medical school graduates, but a lesser currency in the market for law school graduates. The difference has nothing to do with the number of medical graduates and hospitals that need to match; the numbers of law graduates and law firms are substantially greater; the numbers of business school graduates and corporate firms, greater yet. Time-of-offer emerges as a currency or is suppressed by the adoption of a centralized matching program because price is not available as a mechanism to clear the market.

\section{c. Fraternity-Sorority Rush}

According to Professor Roth, in the 1800 s, college fraternities and sororities only admitted seniors to membership. Competition among them, however, led to unraveling of recruitment dates, which led to the coining of the word "rush" to describe the process. Professor Roth explains further that, today, fraternity and sorority recruitment begins as soon as students arrive on campus. Since students today can become members in their first college year, unraveling problems have disappeared. ${ }^{288}$

Despite the apparent absence of current timing issues, it is obvious that the terms of trade in the market for fraternity or sorority membership are quite constrained. Like a judicial clerkship, an invitation to join a fraternity is a takeit-or-leave-it offer. Price and quality are not negotiable. Time-of-offer, were it relevant to today's market, could serve as an available term of trade.

\section{d. Articling Law Students in Ontario}

It is a requirement to join the practicing bar in Canada for a student to serve between eight and twelve months as an articling clerk for a law firm, prior

288 The summary here comes from Roth \& Xing, supra note 11, at 1019-20. See also Susan Mongell \& Alvin E. Roth, Sorority Rush as a Two-Sided Matching Mechanism, 81 AM. ECON. REV. 441 (1991). 
to becoming a regular associate of the firm. ${ }^{289}$ According to Professor Roth, appointment dates for articling clerks began to unravel in the $1970 \mathrm{~s}^{290}$ In 1986 , a matching program was introduced in Toronto. ${ }^{291}$ In subsequent years, however, the market has adjusted so that students work for the law firms with which they will clerk in the summer following their second year of law school. ${ }^{292}$ Professor Roth describes these summer clerkships as a form of unraveling from the centralized match. ${ }^{293}$

Table 8: Salaries of Articling Clerks, Ontario,* 1991-2002**

\begin{tabular}{lrrr}
\hline Year & Low & High & Range \\
\hline 1991 & $\$ 365$ & $\$ 775$ & $\$ 410$ \\
1992 & $\$ 450$ & $\$ 800$ & $\$ 350$ \\
1995 & $\$ 15,000$ & $\$ 40,300$ & $\$ 25,300$ \\
1996 & $\$ 24,000$ & $\$ 45,500$ & $\$ 21,500$ \\
1997 & $\$ 15,000$ & $\$ 42,900$ & $\$ 27,900$ \\
1998 & $\$ 27,800$ & $\$ 44,200$ & $\$ 16,400$ \\
1999 & $\$ 10,000$ & $\$ 52,000$ & $\$ 42,000$ \\
2000 & $\$ 24,000$ & $\$ 52,000$ & $\$ 28,000$ \\
2001 & $\$ 18,000$ & $\$ 57,200$ & $\$ 39,200$ \\
2002 & $\$ 20,000$ & $\$ 78,000$ & $\$ 58,000$ \\
& $*$ The geographic aggregation for salary reporting varied year by year. 1991-1992: Southern \\
Ontario; 1995-1997: Ontario; $1998-1999:$ Toronto; 2000-2002: Ontario. & \\
**1991-1992 are weekly salaries; $1995-2002$, ten-month salaries. & \\
Source: Derived by author from National Compensation Survey, CAN. LAW., various years (on
\end{tabular}
file with author).

The articling market provides an interesting example of the absence of unraveling. The Dean of Placement at the University of Toronto Law School, Bonnie Goldberg, has informed me that, though the centralized match remains in place, it has become obsolete. ${ }^{294}$ As Professor Roth reported, students typically will article with firms with which they have worked during earlier summers. In addition, however, a review of the articling clerk market shows

289 Bonnie Goldberg, Qualifying in Canada: The Articling Requirement, NALP BULL., Nov. 2001, at 6; Roth \& Xing, supra note 11 , at 1024.

290 Roth \& Xing, supra note 11, at 1024.

291 Id.

292 Id.

293 ld. Unraveling from a matching mechanism is what defines Professor Roth's stage 4 market. Id. at 997.

294 Telephone Interview with Bonnie Goldberg, Assistant Dean Career Services, University of Toronto Law School (Nov. 22, 2002). 
that there appears to be substantial salary flexibility in the market. Table 8 above shows the range of salaries for articling clerks in Ontario for reported years since 1991.

The substantial differences between low and high articling clerk salaries indicates that price is an available currency in the clerk market to express differential intensity of prefenence by law firms and clerks. Time-of-offer is not needed to clear the market. As a consequence, the market matching mechanism, otherwise designed to control the use of the time-of-offer currency, becomes obsolete.

\section{e. College and Professional Athletes}

Professor Roth describes the recruitment market for college and, separately, professional athletes, not as exactly suffering timing problems, but as markets in which there are regulations on timing both of the time of transaction and of the age at which certain players can be recruited. The NCAA, which regulates college athletics, places strict limitations on the dates during which college coaches can recruit high school athletes, and strictly enforces an announcement date, before which no high school student can commit to a college sports program ${ }^{295}$ though-not reported by Professor Roth-there is substantial pre-announcement commitment activity. Professional sports leagues placed limitations on the age below which no athlete was allowed to join professional sports, though these age limitations have been largely relaxed in recent times. Thus, teams in the National Basketball Association can draft high school students; ${ }^{296}$ National Football League teams can draft college undergraduates at least three years removed from high school.

These respective forms of regulation, of course, suppress the use of timeof-offer as a mechanism for recruitment to clear the market. It is evident, in the context of college recruitment, that there are limited terms of trade to otherwise serve the market-clearing role. The NCAA severely constrains both financial and in-kind benefits available to college athletes. Given these constraints, the college recruitment market might resemble the market for judicial clerks where time-of-offer could otherwise benefit various of the parties.

The professional sports restrictions can be similarly explained. The professional sports leagues suppress the terms of employment transactions more systematically though the institution of the draft, which eliminates all negotiation over entry-level positions; salary-caps and the like enforce these prohibitions. Interestingly, at later points in the team-athlete employment relationship, for example when players become free agents able to negotiate

295 Roth \& Xing, supra note 11, at 1025.

296 Major league baseball teams had commonly drafted high school students, though often only to retain rights to them during the student's college years. $I d$. at 1025 n.63. 
with other teams, it is not necessary for the leagues to strictly regulate time-ofoffer since price becomes an active currency in the market.

\section{f. College Football Bowl Games ${ }^{297}$}

I discuss Professor Roth's college football bowl game example last because it is such a peculiar market. Professor Roth describes unraveling and subsequent market regulation in the allocation of teams to post-season bowls, choosing as his principal example the $1990-1991$ bowl season. ${ }^{298}$ Prior to that season, because of concerns about unraveling, the NCAA-which regulates college football-established a "Pick-em Date," November 24, a date just prior to the final two games of the regular season before which no bowl could extend an invitation. During the 1990 season, however, it was reported in the press that, thirteen days prior to the Pick-em Date, the Orange Bowl had entered an agreement with Notre Dame. At that time, Notre Dame was ranked first in the country and Colorado (then, the favorite of the Big Eight Conference, to which the Orange Bowl was contractually committed), ranked second. This would have given the Orange Bowl a game between the two best teams in the nation. Following the agreement, however, Notre Dame lost a game and ended the regular season ranked fifth. The team ranked second at the end of the season, Georgia Tech, ended up playing the number nineteen team, Nebraska, in the Citrus Bowl. According to Professor Roth, the unraveling led to inefficient matching preventing the first and second best teams from playing each other, requiring a subsequent opinion poll to determine which team would be regarded as the season's national champion. Similar problems during succeeding seasons led to proposals to centralize bowl game control, culminating in the adoption of the Bowl Championship Series (B.C.S.), now in effect. ${ }^{299}$

The college bowl market is somewhat unusual. College football teams compete in various conferences organized generally geographically among schools of similar size. Bowl games are played at the end of the conference season among the champion teams of each conference and, in lesser bowls, among second- and third-place conference teams. The bowl games are organized in major, chiefly southern, cities, one per city, and are played on various dates from the end of the regular conference season in early December until, today, just after New Year's Day. To maximize television revenue, dates and times are chosen so as not to conflict with other bowl games (or with NFL games).

297 My understanding of this market has been greatly aided by discussions with Steven E. Ehrhart, Executive Director of the Liberty Bowl, Memphis, Tennessee.

298 See Roth \& Xing, supra note 11, at 1009-12 \& tbl.2 for their discussion of the 1990-1991 season, which this Section summarizes.

299 The Roth and Xing paper was published prior to adoption of the B.C.S., though they discuss some precursors. $I d$. at 1013 . 
Although there are some variations, the largest and oldest bowls are played last in the season and are regarded as the most prestigious. Although some bowls are proprietary, most are organized as community non-profits pledging $75 \%$ of net television and gate revenues to the two competing teams.

Competition among the bowls is quite constrained. Most of the bowls have established contractual alliances with specific conferences; some, like the Orange Bowl in 1990, retain discretion to choose at least one team at-large. The extent of price flexibility in attracting an at-large team, however, appears very limited. Gate revenues are basically fixed because of fixed stadium size. Television revenues appear largely fixed according to the date and time established for the bowl. As a consequence, time-of-offer can emerge as an available currency.

Professor Roth's conclusion that the use of time-of-offer as a currency leads to inefficiency-the failure of the first- and second-ranked teams to play each other-requires some interpretation and is not obviously supportable. That failure is an artifact, first, of the seeming fan desire to designate one team as the national "champion",300 and, second, of the decision of the NCAA not to organize a championship football tournament. The logistics of such a tournament would be difficult - for example, it requires six sets of games to determine an NCAA basketball champion, and a football team seldom plays games less than a week apart. Certainly, there is substantial fan interest in identifying a single football champion, though even where a championship game can be contrived, it pits teams according to rankings, not victories through a tournament. Moreover, it is not obvious where efficiency is measured in terms of audience interest or aggregate television revenues that a game pitting the first- and second-ranked teams will outdraw separate games requiring a subsequent qualitative evaluation to name a single "best" team.

The current B.C.S. has been organized by an agreement of six conferences, as well as by ABC and ESPN, television companies possessing contractual rights to broadcast twenty-five of today's twenty-eight bowl games. The agreement provides for the first- and second-ranked teams to play for a championship, but at the expense of any competition among the bowls and to the exclusion of almost all teams from conferences other than those six. Timeof-offer is suppressed here by a regulatory-like agreement among the largest conferences and the networks possessing broadcast rights. ${ }^{301}$

300 Of course, each conference has a champion, determined by the outcome of regular season games or by a post-season toumament.

301 Discussion with Steven E. Ehrhart, supra note 297. Note that I ignore a brief discussion in Roth \& Xing of child marriage in various cultures as a form of unraveling. Roth and Xing supra note 11 , at 1026 . Whether this cultural practice should be considered in all contexts as market unraveling or is better understood in relation to other cultural features, such as tribe or family alliances, wealth aggregation, and the like, is no doubt a difficult question. But see Nepal: The Bride Wore Diapers, N.Y. TIMES, Feb. 26, 2003, at A6: 


\section{Markets Where Timing Is a Means of Avoiding Regulation}

This Section discusses other of Professor Roth's examples of unraveling, here explaining them by a different sort of market restriction. In the following examples, the timing of market transactions serves as a means of avoiding forms of market-suppressing regulation.

\section{a. Medieval Commodity Markets}

Professor Roth identifies an ancient form of regulation of unraveling in the medieval prohibition of the practice of forestalling, defined as buying or selling certain commodities prior to their delivery at an organized market. Professor Roth provides two examples of the prohibition:

Thus at Norwich no one might forestall provisions by buying, or paying "earnest money" for them before the Cathedral bell had rung for the mass of the Blessed Virgin; at Berwick-on-Tweed no one was to buy salmon between sunset and sunrise, or wool and hides except at the market-cross between 9 and 12; and at Salisbury persons bringing victuals into the city were not to sell them before broad day.

This example obviously illustrates restrictions imposed in order to create an organized market.

Professor Roth's second example is somewhat different.

In 1233 Eve de Braose complained that Richard Fitz-Stephen had raised a market at Dartmouth to the injury of hers at Totnes, as ships which ought to come to Totnes were stopped at Dartmouth and paid customs there. No decision was reached, and eight years later Eve's husband, William de Cantelupe, brought a similar suit against Richard's son Gilbert. The latter pleaded that his market was on Wednesday and that at Totnes on Saturday; but the jury said that the market at Dartmouth was to the injury of Totnes... and also that cattle and sheep which used to be taken to the Totnes market werc now sold at Dartmouth; the market at Dartmouth was therefore disallowed. $^{303}$

The Totnes-Dartmouth dispute appears to involve competition between markets. The timing of transactions is an issue solely because the Dartmouth market is open on Wednesdays, the Totnes market, on Saturdays. The existence of the Dartmouth market, however, diverts sales from Totnes.

\footnotetext{
A 6-month-old girl and a 3-year-old boy were married in a southern village despite laws against child marriages, the newspaper Taja Khabar reported. The parents, members of a farming caste, arranged the marriage ... because they feared that the children would be unable to find partners later in life, the newspaper said.
}

This example clearly represents Professor Roth's unraveling, not implausibly the consequence of the concern about future limited terms of trade in the marriage market.

302 Roth \& Xing, supra note 11, at 1027 (citing SALZMAN, supra note 169, at 76).

303 Id. at 1028 n.68 (citing SALZMAN, supra note 169, at 132-33). 
Is it useful to interpret these as examples of market unraveling? I think not. These restrictions are more readily understood when the institutional structure of medieval markets is clarified. Medieval markets were not simply organized areas defined to facilitate market exchange. They were monopolies granted (sold) by the king as revenue. The monopoly grant generated the greatest revenue for the holder of the grant and, thus, the highest price to the king. As Franklin Jones describes it,

Fairs and markets could only be held by grant of the Crown... No markets were permitted within six and two-thirds miles of each other... The owners of the markets or fairs usually exacted tolls on sales and a charge known as stallage for space for stalls in which to display goods. If they had a monopoly in specified territory their charges were often excessive. The obstruction of those coming to market so as to deprive the market owner of his stallage and the people of an unrestricted market in which to buy and sell, was called forestalling and was unlawful, both at the common law and under the statutes.

Similarly, according to Schueller, "[e]very deal concluded outside an authorized market place or outside official market hours was looked upon as tax evasion." 305

The prohibition of forestalling, thus, was a means of protecting the revenues generated from the operation of monopoly markets. ${ }^{306}$ The practice

304 Franklin D. Jones, Historical Development of the Law of Business Competition, 35 YALE L.J. 905, 906-07 (1926). William Letwin makes a similar point. According to Letwin, forestallingsales outside the organized market -

was abhorred... by those who saw in it an infringement of their privileges as owners of markets. Rights to hold markets were granted or confirmed by the Crown, and established local but powerful monopolies. What was given was not the mere right to hold a market, but an exclusive right. . . The owners of markets often had an intense interest in protecting their exclusive rights, for some of them had the right to charge a toll on certain goods sold in the market, and all of them were entitled to charge fees for market stalls put up on their land. To hinder sellers from coming to a market was therefore to deprive the owner of the market of stallage fees.

William LETWIN, LAW AND ECONOMIC POLICY IN AMERICA 35 (1965).

305 George H. Schueller, The New Antitrust Illegality Per Se: Forestalling and Patent Misuse, 50 ColuM. L. Rev. 170, 176 \& n.45 (1950) (citing "the case against Alice de Corncet (date unknown), in 5 SELDEN SOCIETY 57 (1891) (defendant bought 'one quarter of wheat outside town, meeting it on the way to market. . . whereby the Bailiffs lose toll')"). Professor Roth's source for his examples makes a similar point: "In all these cases, the chief cause of complaint was the loss of tolls ... the main source of profit of a market ..." SALZMAN, supra note 169, at 133.

306 The practice of forestalling extended to other activities as well, in particular buying goods at some point outside a market with an ambition of selling them in the market, presumably at a higher price. This form of forestalling resembles the crime of engrossing (buying large quantities of commodities for resale) and was, purportedly a mechanism for medieval price control. See 4 WILLIAM S. HOLOSWORTH, A HISTORY OF ENGLISH LAW 375-79 (2d ed. 1937); LETWIN, supra note 304; Wendell Herbruck, Forestalling, Regrating and Engrossing, 27 MICH. L. REV. 365 (1929); Jones, supra note 304; Schueller, supra note 305. Principally, these were prohibitions on the trade of middlemen or speculators. Adam Smith devastatingly criticized these prohibitions on the grounds that removing the middlemen impeded price discovery and the ability of prices to fluctuate appropriately with supply and demand by preventing price information from reaching the market. 2 ADAM SMTTH, 
itself was a form of unraveling, but here unraveling to avoid the tolls and taxes imposed upon transactions in the market. As shall be discussed in more detail next, transactions occurring outside markets may be viewed as a form of freeriding on the existence of the market. An example would be a transaction between parties who found each other just outside the market gate. In contrast, other of these restrictions may simply shore up the market monopoly. For example, it is not evident that the sale of salmon after dark-prohibited in Berwick-on-Tweed in Professor Roth's first example-represents free riding. Similarly, the dispute between the owners of the markets in Totnes and Dartmouth does not involve free riding. One market is competing with another; the one with the monopoly grant from the king prevailed, surely to the detriment of market participants. In these examples, sales outside the marketthe purported unraveling-represent efforts to avoid the deleterious effects of the monopoly tolls and thus, are market enhancing-again, not a sign of some market imperfection. ${ }^{307}$

\section{b. Chicago Board of Trade}

Professor Roth's final example is the market restriction exposed in the famous Chicago Board of Trade antitrust case. ${ }^{308}$ The Justice Department prosecuted the Board under the Sherman Act for adopting a rule that created a special period - the "call"- - just after regular hours, for the sale of grain in transit to Chicago ("to arrive" grain), but constrained Board members, during the period from the end of the call to the beginning of the next business day, from entering transactions for the sale of that grain at any price other than the closing price at the end of the call. ${ }^{309}$ The case is significant in antitrust law as representing the victory of those members of the Supreme Court who wanted more flexibility in Sherman Act analysis over those wanting every form of price restriction to constitute a violation. The case establishes the basic interpretive contours of the Rule of Reason, weighing the benefits of some market restriction against any anticompetitive effects. The example is significant to Professor Roth as an illustration showing that market limitations relating to price, like other regulations of market operation-such as the definition of the regular hours for Board trading-can enhance the market. ${ }^{310}$ The analogue to

\footnotetext{
AN INQUiRY INTO THE NATURE aND CAUSES of THE Wealth of NATIONS, bk. IV, ch. 5, at 104-11 (James E. Thorold Rogers ed., Oxford Clarendon Press 1869).

307 As a related example, Roth and Xing note the example in the post-Soviet Union economy of consumers making deals directly with suppliers, rather than with the shops to be supplied. This practice is likely to have derived from the imposition of price or supply restrictions on products; Roth and Xing do not explain. Roth \& Xing, supra note 11, at 1028.

308 Bd. of Trade v. United States, 246 U.S. 231 (1918).

309 Id. at 236-37.

310 Roth \& Xing, supra note 11 , at 1028.
} 
unraveling is the sale by Board members of "to arrive" grain after regular Board hours on one day, but before Board hours on the next.

The current understanding of the practice and of the case mirrors the Roth interpretation. Thus, the rule restricts trade over some range: limiting sales to the closing price means that, if there are supply or demand changes (or predictions of them) that might change the effective grain price between the end of the call period and the opening of the Board the next day, transactions involving Board members will have to wait. The restriction is regarded as market enhancing, however, because-presumably like the creation of the Board of Trade as a market itself-it facilitates trade by forcing transactions into the market. On this reasoning, in an excellent article explaining the operation of the rule, Peter Carstensen concludes that it constituted a restraint "ancillary" to the rules creating the market. ${ }^{311}$

Both Carstensen and Richard Zerbe have shown that the rule was imposed by the Board as an effort of Board members who were commission merchants to gain a greater share of grain sales over Board members who owned grain elevators. ${ }^{312}$ Prior to adoption of the rule, the grain elevator members dominated grain sales after Board hours because of advantages from vertical integration from their elevator operations. By constraining the price at which they as Board members could buy grain (to the call's closing price), more sales were shifted to regular Board hours when non-elevator commission merchants were better able to compete.

It is an interesting analytical question whether this form of restriction should be regarded as market-enhancing. Surely, creating a market is marketenhancing. For example, defining the hours during which the market will be open-even if limited to less than twenty-four hours per day-is marketenhancing in the sense that it creates a known time for the conduct of market transactions. Like other forms of centralized markets, defining time and place announces the conditions under which parties can come together to most effectively buy or sell.

Analytically, however, restrictions such as the "call" rule are different and restrain trade rather than enhance it. The rule is superficially similar to the announcement of limited times of market operation as it forces transactions into the organized market. The difference is that it achieves this effect by prohibiting transactions at other times that some parties would prefer to enter. The establishment of the operating hours of the Board of Trade-or of any other

311 Peter C. Carstensen, The Content of the Hollow Core of Antimust: The Chicago Board of Trade Case and the Meaning of the "Rule of Reason" in Restraint of Trade Analysis, 15 RES. L. \& ECON. 1 (1992). Richard Zerbe, in essence, concludes similarly, though he emphasizes that the "call" rule was incidental to the adoption of fixed commission rates by the Board which today would be a clear antitrust violation. Richard O. Zerbe, Jr., The Chicago Board of Trade Case: 1918, 5 RES. L. \& ECON. 17 (1983).

312 Zerbe, supra note 311; Carstensen, supra note 311. 
centralized market-allows anyone wanting to transact in that market to come and take advantage of market benefits: the presence of greater numbers of buyers and sellers enhancing competition and reducing price and price dispersion. Parties that choose to transact after market hours, however, do so after concluding that the benefits of trade are greater at the after-hour time than waiting for the market to open. By constraining such transactions, restrictions like the "call" rule reduce aggregate welfare. The transactions that the call rule sought to prohibit do not represent free riding on the organized market because, by definition, they were transactions at prices other than those established by the market itself, thus deriving from separately acquired information or prediction.

As in other contexts, the unraveling here represents opportunities for parties to gain in contrast to transactions subject to the constraints of the Board of Trade. The "call" rule, then, resembles the prohibition of forestallingbuying and selling outside the market. In this respect, it also resembles constraints on the time at which judges can hire clerks. In each of these contexts, though superficially the restrictions appear to enhance the market by forcing transactions into it, each actually constrains market transactions that parties would otherwise prefer to enter.

\section{Summary}

All of the markets identified by Professor Roth as possessing timing disturbances (at least all for which there is sufficient information) can be seen to be characterized by constraints on alternative terms of trade. Time-of-transaction becomes relevant because other mechanisms to clear the market-most notably, price-are restricted in some way. These timing phenomena reflect the working out of market forces enhancing aggregate welfare and are not market failures suggesting some form of welfare loss that can be cured by regulation. To the contrary, welfare would be enhanced by eliminating the restrictions on the use of price as a market-clearing device.

\section{Judicial Disrepute and the Ethics of Practices in the Market for Clerks}

Finally, this Part attempts to address carefully the accusation that the operation of an unregulated market for clerks casts the federal judiciary into disrepute. This accusation formed an element of the analysis of Judges Becker, Breyer and Dean Calabresi, ${ }^{313}$ was central to the criticisms of the market by

313 Becker et al, supra note 20 , at 210 \& $n .8$ (quoting Judge Goodwin's analogy of the market to a calf scramble); id. at 214 (citing Letter from Geoffrey $R$. Stone, Dean, University of Chicago Law School, to Judge Becker 1 (July 7, 1993) (on file with author) ("The existing state of affairs is nothing short of absurd. It demeans the federal judiciary ....")). 
Judges Wald ${ }^{314}$ and Oberdorfer, ${ }^{315}$ and was a principal normative conclusion of the Harvard-Chicago Study. ${ }^{316}$ Even Judge Kozinski, an avid defender of an unregulated market, conceded that the "system may be conducive to undignified behavior or it may reward a lack of collegiality."

In virtually all treatments of the clerkship market, this criticism is levied generally against the process that compels competition among judges to secure the most able clerks. Thus, Judge Wald criticizes the "intense competition among judges" and the "covert maneuvering by judges and applicants;", Judge Oberdorfer, that "judges extend offers in unseemly haste out of concem that their colleagues on the bench will make off with their prime prospects;";19 Judges Becker, Breyer and Dean Calabresi, the "frenzy of offers and acceptances [that] ensued within minutes of the [May 1, 1990] noon hour [set date],; 320 and the Harvard-Chicago Study, the "frenzy of hiring" where "judges scheme to outmaneuver one another in the effort to hire desirable clerks." 321

In evaluating these criticisms of the clerkship market, however, it must be seen that, though they seem to be complaints about the competitive process itself, the content of the criticisms is not exactly that the process forces judges to compete. Neither of the two principal proposed reforms-an established set date, such as the current agreement to restrict applications until after Labor Day, or a centralized computer matching system-eliminates competition among judges. They, instead, channel that competition: the set date, to a later time than that in which it would otherwise occur; the computerized match, both to a later time and through a selection process that, as discussed, removes time-of-offer as a currency, reinflating the competitive advantage of the prominent judge. Moreover, there is no obvious normative basis for shielding the judiciary from having to compete over staffing.

If, then, the generalized criticisms of the process are not immediately supportable, perhaps it is some set of individual practices of judges or applicants that taints the conduct of the clerkship market. After a careful reading of the literature, including the detailed narrative complaints presented in the

314 "Maybe judges have to look harder into their own realities and perceptions to see if the gamesmanship at which a few excel is really worth the angst and perceptions of unseemly competition that now cloud the clerkship selection process." Wald, supra note 6 , at 163.

315 "The current anarchic process by which federal judges select their law clerks is inefficient, expensive, disruptive, and demeaning." Oberdorfer \& Levy, supra note 6, at 1108; see also id. at 1097 (noting that judges must "inspire and maintain firm public confidence in the decisions that they make and the way that they make them. The present method used by federal judges to select their law clerks unnecessarily jeopardizes that confidence."); supra text accompanying note 50.

316 Harvard-Chicago Study, supra note 7, at 798-99.

317 Kozinski, supra note 6, at 1713.

318 Wald, supra note 6, at 152.

319 Oberdorfer \& Levy, supra note 6, at 1098.

320 Becker et al., supra note 20, at 211.

321 Harvard-Chicago Study, supra note 7, at 796. 
Harvard-Chicago Study, I have listed below all of those specific practices that the various authors have criticized.

\section{Practices regarded as Unethical in the Current Clerkship Market}

\section{A. Interview Scheduling Practices}

1) Judge asking applicant to sneak into courthouse on Sunday because the judge's court had agreed to comply with a later set date;

2) Judge insisting on interview at conflicting time with interview scheduled with other judge; ${ }^{323}$

3) Judge canceling interview after applicant paid for trip to judge's city; ${ }^{324}$

4) Judge interviewing applicant as back-up where all available positions had been offered to others; ${ }^{325}$

B. Substantive Interviewing Practices

5) Judge "badmouthing" other judges or informing applicant of adverse information about a competing judge ${ }^{326}$

C. Offer Practices

6) Judge promising to keep offer open until applicant interviewed with favored judge, but reneging on the promise; $^{327}$

7) Judge extending more offers to applicants than positions possessed, with the first of those to accept receiving the positions; $^{328}$

8) The extension of short-fuse or exploding offers; ${ }^{329}$

322 Id. at 835 tbl. 15.

323 Kozinski, supra note 6, at 1717.

324 Harvard-Chicago Study, supra note 7, at 835 tbl.15.

325 Id.

326 Margolick, supra note 22; Kozinski, supra note 6, at 1717. David Margolick also reports judges as "spying and poaching" on other judges, though he is the only critic to list these offenses. It is not clear what constitutes "spying;" perhaps, seeking to learn of candidates identified by another judge, rather than discovering the candidate personally. This form of free riding can be condemned though, again, Margolick's is the only reference to the practice. Margolick also neglects to define or identify "poaching." In other contexts, the term implies interference with some property right. If a judge induces breach of an agreement, it is contemptible. Again, there are no references in the literature to this practice other than Margolick's

327 Harvard-Chicago Study, supra note 7, at 819-20. Whether the judge actually reneged on the promise or merely indicated displeasure that the applicant still wanted to interview the other judge despite the first judge's offer is not clear from the description.

$328 \quad$ Id. at 819.

329 Harvard-Chicago Study, supra note 7, at 818; Becker et al., supra note 20, at 222-23; Kozinski, supra note 6, at 1716; Wald, supra note 6, at 156. But see supra Table 2, (showing relatively low percentage of judges employing exploding offers). 
9) The use of other undefined "strong-arm" tactics. 330

To date, none of the critics of the clerkship market has carefilly analyzed the ethical content of these practices. Some are obviously questionable. For example, 5) above, badmouthing other competitors, is objectionable in any market, at least if the adverse information transmitted is untrue. If the information is accurate, the judgment is more difficult. Similarly, it is not difficult to condemn practice 1), above, the request by a judge for the applicant to sneak into chambers, because it represents, essentially, cheating on the decision of the judge's court to comply with a later set date. This ethical violation, however, derives not from the inherent operation of the market, but from regulation of the market. The judge, clearly normatively conflicted with the set date, proceeded around it. Nevertheless, there is no ethical defense for the judge to avoid confronting the normative disagreement over the set date honestly, and to bring the applicant in through the front door, rather asking the applicant to "sneak" into the courthouse.

Similarly, many of the other seemingly high-handed practices by judges are likely to be exacerbated, not solved, by reforms such as the set date. As discussed above, established set dates intensify competitive pressures because of the constrained period in which search is available. In contrast, some of these practices-such as the examples of interview and offer manipulation, including short-fuse offers-might well be abated by the establishment of a centralized match because, again, the match suppresses the significance of time in the market process.

In another light, however, it is important to identify in what contexts these various competitive practices might be questioned. As described, the market for clerks is one in which, because it is merely a one-year position and because applicants' records are likely to be similar over a large range, any judge is likely to find many applicants whose qualifications are largely indistinguishable. In a context of relative indifference among applicants, the apparent high-handed behavior of judges can be understood. Insisting on a conflicting interview, interviewing back-ups, offering more positions than are available to the first of the applicants who accepts them, short-fuse offers, all are comprehensible in a market in which there are limited real differences among the applicants available to the judge. ${ }^{331}$

330 Kozinski, supra note 6, at 1729.

331 The Ad Hoc Committee on Law Clerk Hiring considered the issue of exploding offers in 2003, but made no recommendation on it, allowing judges to determine the offer process. See HARRY

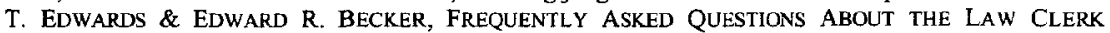
HIRING PLAN, http:/www.cadc.uscourts.gov/bin/lawclerk/lawclerkpdf/faqs_for_2004.pdf (last visited Nov. 17, 2004). 
Are such practices unethical? They may be unethical if they depart substantially from the reasonable expectations of the applicant. Thus, if a judge encourages an applicant to fly to the judge's city for an interview, but fills the available position while the applicant is in flight, 3) above, the reasonable expectations of the applicant have been breached. Yet, if the judge had informed the applicant that the interview was currently available, but at the applicant's risk of the position being filled prior to arrival, we would think entirely differently of the event. Similarly, if an applicant knows that a judge extends short-fuse or exploding offers and still seeks an interview with the judge, the short term over which the offer is extended cannot be regarded as unfair.

This suggests that, in the absence of other reforms, a helpful corrective to practices of questionable defensibility described above is increasing the information available to applicants about the practices of each federal judge. If applicants know that a judge has had a history of interviewing back-ups, after all positions are otherwise filled, 4) above, ${ }^{332}$ then the applicant will know to inquire of the judge, prior to flying to the court, how many positions remain open and what the prospects of advancing from back-up status actually are. Similarly, if an applicant knows that a judge reneges on promises to keep offers open, 6) above, the applicant can decline the interview with the judge or only schedule it after interviewing with the favored judge. Many years ago, Judge Kozinski recommended that law schools become repositories of market information about the hiring practices of judges. ${ }^{333}$ It remains a sensible reform. $^{334}$

All of the practices complained about above are practices of judges. But judges cannot compel applications. Applications are in the hands of aspiring clerks. Armed with sufficient information about individual judicial practices, applicants need not expose themselves to interview scheduling or offer exploitation by the federal judiciary. As in many other contexts, market information allows consumers to police and select among the parties with whom they might deal.

\section{Conclusion}

The market for judicial clerks is an unusual market, but it is not an incomprehensible one. Like many other assortative matching markets, both judges and clerks face uncertainty over the success of a match. Given restrictions on the availability of alternative terms of trade to reflect intensity of

332 It makes no sense for the judge to interview a back-up unless there is some chance that the position might open, complicating the evaluation of the practice.

333 Kozinski, supra note 6, at 1724-28.

334 The Administrative Office has attempted to organize a centralized database of hiring schedules-just one element of the information I am discussing-although the Harvard-Chicago Study is generally dismissive of the effort. Harvard-Chicago Study, supra note 7, at 861-62. 
preference-here, inevitable restrictions on the availability of price, set by Congress-time-of-offer emerges as a currency. The time currency rewards judges who develop skills or techniques of recognizing talent based upon limited information. Distributional consequences result from the exercise of those skills, similar to the distributional consequences of the exercise of predictive skills in other markets-like real estate or securities-in which predictive ability allows early buyers to gain advantage over later ones. The introduction of restrictions on the time-of-offer currency, like any other restriction on terms of trade, will change the allocative outcomes of the market for clerkships as well as other markets, but can generally be predicted to reduce aggregate welfare. 